\title{
Boosting Sustainability in Egypt by Developing Initiatives to Promote Smart Energy Systems
}

\author{
USAMA KONBR $^{(1)}$, EHAB MAHER ${ }^{(2)}$ \\ (1) Assoc. Prof., Department of Architecture, Faculty of Engineering, Tanta University \\ (2) Researcher, Department of Architecture, Faculty of Engineering, Tanta University \\ ${ }^{(1,2)}$ Department of Architecture, Faculty of Engineering, Tanta University, EGYPT
}

\begin{abstract}
Egypt is striving to improve energy exports and efficiency. Smart Buildings (SBs) promote sustainability and represents an essential pillar of smart cities. Smart Systems (SSs) are the physical infrastructure of SBs, serving the integration between their components and the users. Smart energy systems (SESs) are among the essential SSs in SBs. This article's aim is boosting sustainability, relying on increasing energy efficiency by harnessing the SESs, which divided into three key divisions: Smart energy management (SEMS), smart energy generating (SEGSs), and smart energy consumption (SECSs). It concluded the features of SESs to analyze several international and local case studies. Then, it developed and checked 35 initiatives of SESs, relying on in-depth local surveys, to address smartness features in energy systems (ESs) according to their priority, availability, and cost. These initiatives represent an appropriate and customized guide to architects, stakeholders, and decision-makers, especially in the Egyptian scope. The study results concluded that only 22 initiatives were achieved by $62.86 \%$ and addressed their efficiencies. The discussion interpreted losing the 16 absent and weak initiatives regarding the technical, economic, and social obstacles to strengthen the current Egyptian unprecedented urban development decision-making.
\end{abstract}

Keywords: Sustainability; Architecture; Smart energy systems; Energy efficiency; Smart buildings; energy management; Egypt

Received: October 29, 2020. Revised: January 3, 2021. Accepted: January 15, 2021. Published: February 4, 2021.

\section{Introduction}

The sustainability issue is of great importance to the United Nations, adopting it globally at the highest level, represented by heads of states and kings. The United Nations emanated global 17 sustainable development goals (SDGs), the entire world adopts these goals. The seventh goal is related to energy; it included a set of sub-goals up to 2030. It aimed to make sure universal access to affordable, reliable, and modern energy services, increasing the share of renewable energy substantially; doubling the global rate of improvement in energy efficiency. Moreover, enhancing international cooperation to advance access to clean energy research and technology, including renewable energy, energy efficiency, and advanced \& cleaner fossil-fuel technology. The energy goal also promoted energy infrastructure investment and clean energy technology, expanding the infrastructure, and upgrade technology for supplying modern and sustainable energy services for all in developing countries [1]

Although energy addresses the most critical issues of today and tomorrow, such as climate change, sustainable development, health and environment, global energy and food security, and environmental protection, conventional energy systems have failed to meet the multidimensional and multidisciplinary requirements of the twenty-first century [2].

Organizations worldwide have primary goals to reduce energy consumption in the buildings sector, as it is responsible for more than $40 \%$ of the world's total primary energy consumption [3]. Energy consumption in the construction sector is mainly responsible for greenhouse gas emissions worldwide, with its negative impact. Whereas all power chains address this problem from management to generation to consumption; Therefore, it is imperative to focus on developing energy issue measures in the construction sectors, with the advantages of its management, generation, consumption, conservation, and savings [4]. 
Unfortunately, little progress has been made at the international level in preparing for this, making it imperative to intensify efforts to develop and implement energy efficiency requirements in general, focusing on the construction sector.

As a logical and natural consequence of the previous, the global trend has recently emerged for those interested in both energy and construction issues with SESs. Research has shown its many advantages, as it includes three dimensions that enhance sustainability: Firstly, the environmental dimension, which makes buildings well adapted to the environment with its natural parts. Humanmade, as it reduces emissions from building and construction activities in search of synergies to reduce carbon in its energy use cycle [5]. Secondly, the social dimension considers the occupants' needs, including providing an environment conducive to social activities and obtaining the necessary internal comfort to suit the constant variables and needs. Thirdly, The economic dimension through its economic feasibility. A previous survey found that SESs can recover their actual value by saving energy in the long term and enhancing sustainability, although using SESs in buildings needs an additional budget at the beginning [6], as shown in Fig. 1 .

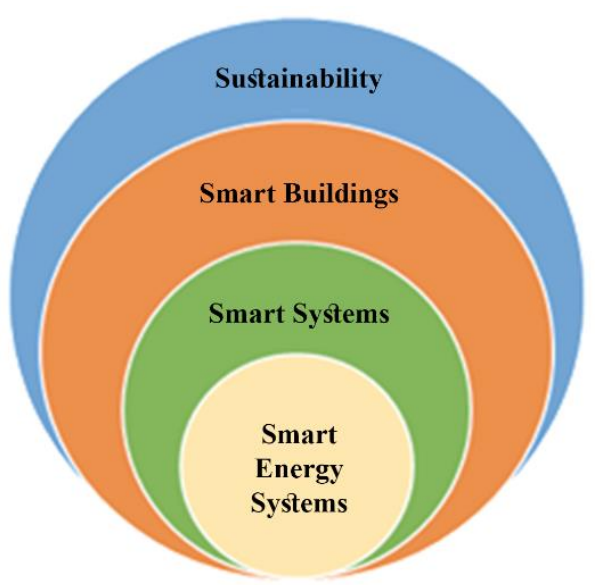

Fig. 1: SESs and sustainability

It is imperative to intensify these efforts to implement these requirements in various Egyptian contexts where the ministries of higher education and scientific research, electricity, energy, and industry strongly sponsor these goals. Egypt's agenda 2030 showed that the energy issue among its most important priorities. This national trend has reflected many research types in energy efficiency. Architecture has taken care of this issue for a long time as significant demand for this goal, so the research point has found itself prominent in Egypt's current scientific research strategy.

The building sector in developed countries is responsible for about $40 \%$ of total energy consumption [3]. This increase seems to be continuing, necessitating increased energy efficiency in buildings. The world faces challenges regarding depleting fossil fuels, placing heavy responsibilities to develop new smart energy solutions [7]. Therefore, this article addresses SESs to boost energy efficiency and sustainability, adopting the latest technologies to provide a productive and cost-effective environment with controlling, monitoring, and optimize building operations and maintenance.

Therefore, this study aimed to harness (SESs) smart energy systems with their environmental, social, and economic advantages to promote sustainability as an end goal by raising energy efficiency as an interim goal. The theoretical study will conclude a general framework that helps develop sets of initiatives for utilizing the SESs in the Egyptian context to enhance buildings' energy efficiency as an entry point to boosting sustainability.

Hence, the applied part examined the existence, importance, and prioritization of the developed initiatives in the Egyptian context through careful surveys, and then the research reached the results, revealing the urgently needed initiatives to enhance the Egyptian energy system. The discussion provided justifications for the absent initiatives to direct the research to its conclusion.

\section{Methods}

This study aims primarily to enhance sustainability by utilizing SESs. It relied on the inductive approach of the sustainability concepts, smart buildings, SESs, and their relationship to achieve that. Moreover, it also relied on a case study approach to address and analyze similar global, Arab, and local cases. The deductive approach was also used in developing the initiatives of smart solutions concerning SESs. On the other hand, the application method, survey, and descriptive-analytical approach are used to develop and check these initiatives in the Egyptian context.

The applied section aimed to analyze the gap between the proposed initiatives and the real situation through the same elements derived in the theoretical section. Moreover, it extended its aims to study, analyze, and document the gap between the available possibilities and the shortcomings of the absent initiative, 
focusing on the justifications and the interpretations for this absence down to the results, discussions, and conclusion in Fig. 2. its specific regional climate. Lighting and water heating have a significant consumption rate [8]. The term SESs appeared in 2000; From 2009 to 2013, the

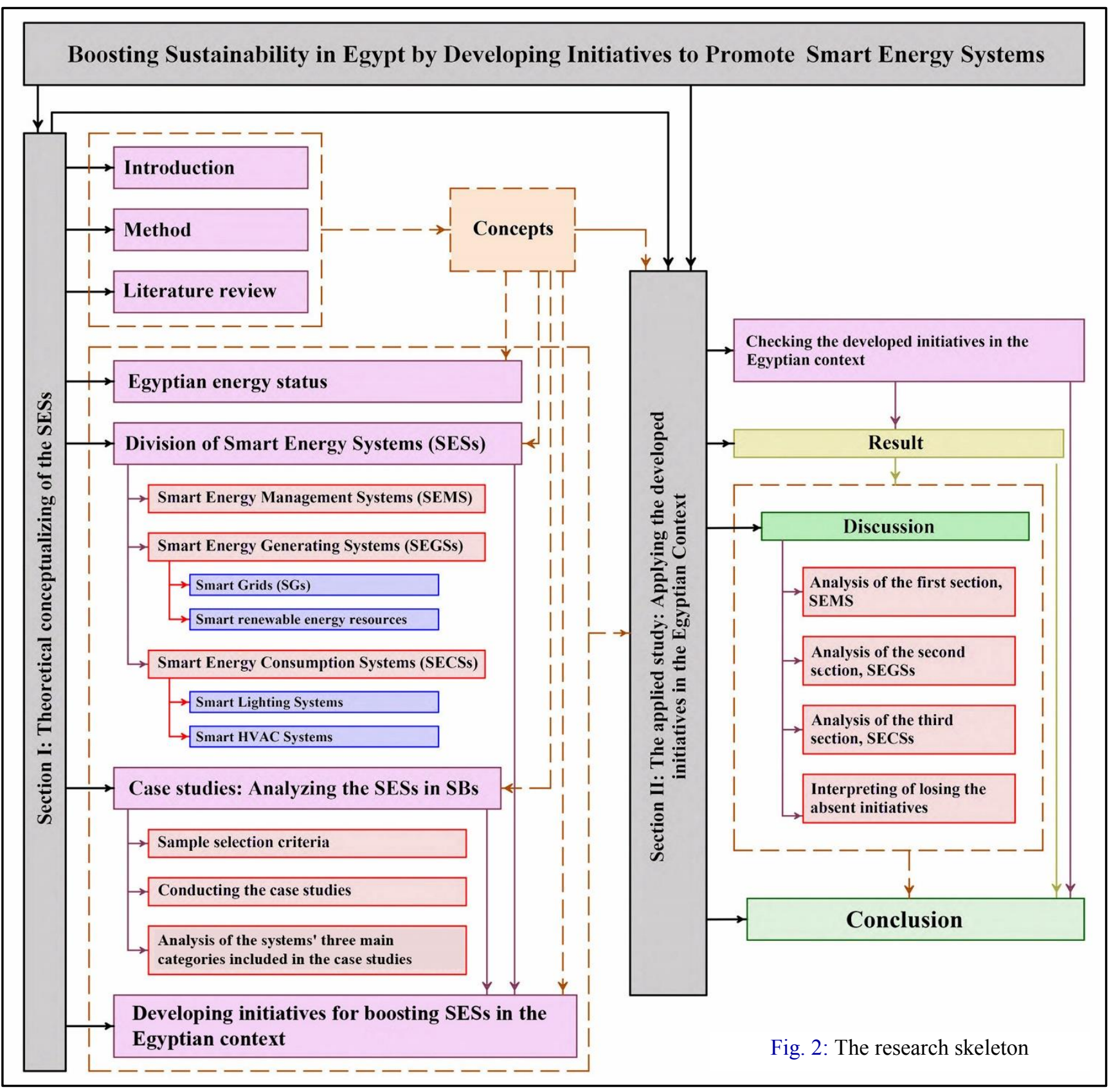

\section{Literature review}

Egypt adopted energy efficiency policies in several sectors [8], taking strides toward exploiting renewable resources to enhance sustainability. Integrated sustainable energy strategy 2035 prompts its capacity to be $42 \%$ of power capacity by 2035 [9]. Many factors can affect total energy consumption caused by using various buildings' complex systems. So, the SESs are mainly installed to rationalize such energy consumption [10]. Egypt's cooling systems have many energy-consumption patterns because of word "smart" became necessary, referring to the wider use of the Control Management Systems (CMSs). After that, the term "systems" took great significance for the term SESs to cover all construction sectors [11].

The study of "renewable energy transport scenarios towards 2050" in Denmark addressed and developed SESs at the CEESA project [12]. SESs had its formal definition in 2014. Later, many articles used this term concerning energy systems simulation, energy efficiency, sustainable transport, and implementing 
SESs for Europe's whole [13]. Then, the relationship between sustainability and SESs was wholly established [14]. It was expected regarding the residential sector to reduce carbon emissions to be under the Paris Agreements to mitigate global warming and alleviate energy poverty [15].

Global interest in SESs has increased as it got its importance at multiple levels by linking the internet of things (IoT) to the SEMS for maximizing energy efficiency through the collective energy information [16]. Moreover, an IoT framework was proposed for SESs, which involved considering users' preferences [10]. A framework was presented of both MultiAgent System MAS and SEMS that made SESs more flexible, adaptable, and extendable to ensure energy optimization [17]. A cloud-Enabled BEMS (CEBEMS) was introduced, where the cloud used computing to improve management mechanisms and energy-saving functionality for SBs [18]. Smart lighting management strategies proposed the achieved energy savings of about $44 \%$ compared to conventional systems [19]. The WinLight app. was designed to enable occupants to customize their luminance preferences and use their mobile devices to control nearby lighting [20].

The benefits of creating a smart HVAC system were presented, which leads to users' thermal comfort with lower energy consumption. The implemented initiative regarding Model Predictive Control (MPC) of HVAC systems in a real environment is based on IoT [21]. It links sensors, controls, and actuators subsystems with the end-user interface remote control through the internet using a remote database server and a control unit [22].

Accordingly, SESs in buildings can directly boost sustainability through energy efficiency, user comfort, and reducing harmful emissions relying on IoT. So, the study divides SESs into three key systems sections: (SEMS), (SEGSs), and (SECSs); as shown in Fig. 2, this study will detail all these sections as follow.

\section{Egyptian energy status}

Egypt's vision 2030, especially in energy, emerged from the sustainable development goals emanating from the United Nations, especially the seventh goal. It aims to achieve a diversified, stabilized, and sustainable economy. Renewable energy has a vital role in integrating the Sustainable Energy Strategy up to 2035 [9]. Egypt developed sustainable green building standards and codes to ensure long-term energy conservation in buildings, which are optionally applied because of poor control [8]. Although the rules and regulations for green and energy-efficient buildings have been settled, there are significant hurdles, such as:

a. Lack of strict energy price control negatively affects energy efficiency economic incentives [8].

b. Green technologies' incremental costs are too high for the low-income population [23].

c. Besides the weak monitoring of the construction and systems installation, the absence of obligation in implementing the green building codes [8].

d. The lack of appropriate educated, professional qualification, and well-trained technical staff; besides the absence of public awareness about enduser needs [23].

e. The growth rate of energy demand in the buildings sector increases by 135\% during 2014-2030. In response, the Egyptian government took bold measures to pursue an energy diversification strategy with increased renewable energy production and energy efficiency [9].

\section{Division of Smart Energy Systems (SESs)}

The study divided the SESs into the next three key systems categories:

\subsection{Smart Energy Management System (SEMS)}

SEMS is installed to manage, control, monitor, and optimize energy usage. This system also depends on collecting data from and for users Fig. 3. It related systems typically account for $40 \%$ of a building's energy usage, and when lighting is included, the ratio

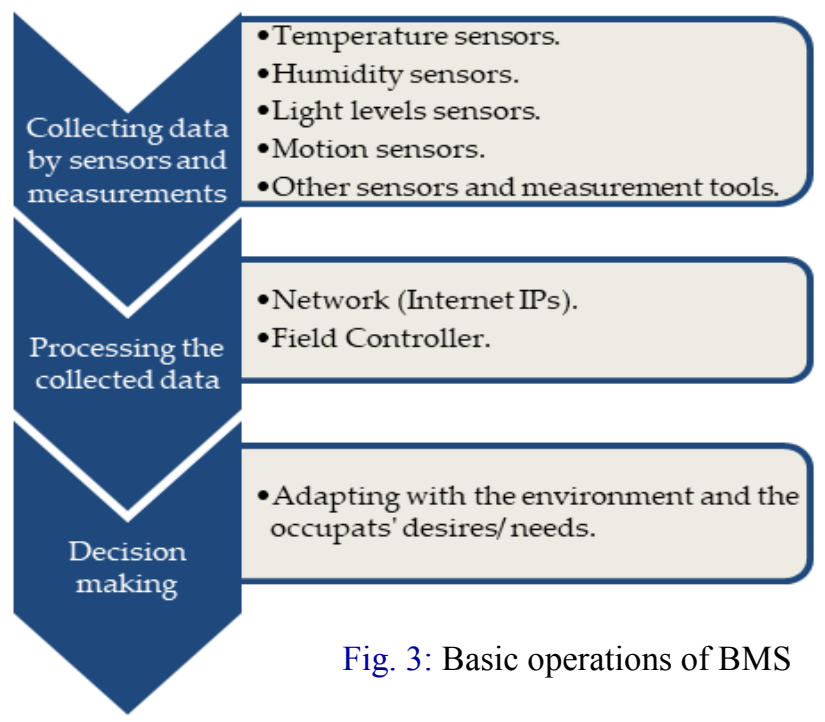


can reach $70 \%$, representing a critical factor in raising energy efficiency [24].

SBs should be designed to specific requirements with a certain context-awareness, as the environment and occupants' status play critical roles [25]. The SEMS could not accommodate growing numbers of end devices on its own, e.g., power equipment and IoT devices, and efficiently emerging energy resources. Uikyun et al. proposed a Fog BEMS to overcome those limitations, which applies an emerging principle of fog computing to a BEMS. Data is not provided from sensors only; also, free and cheap data resources available on the web, as various activities extracted information on connected computers to the internet, weather forecasts, materials used in construction and finishing, the size of architectural spaces, personnel schedules, calendars, room, or building reservation systems [26].

\subsection{Smart Energy Generating Systems (SEGSs)}

It is addressed in the Egyptian scope through:

\subsubsection{Smart Grids (SGs)}

The successful development of SGs involving SBs is one basis of smart cities, where smart IPs with sensors and other equipment overlay the electricity grid. The microgrid solution will improve hundreds of households in a building or an area so that private management of household demand is integrated; this requires integrated controls on building automation [27]. These users' names are changed to "prosumer" to distinguish them from ordinary consumers who often burden the grid and producers. It will enhance network management, limit the electricity losses, prevent outages, load-shed, and provide customers with in-house information and tools, relying on smart meters that enhance energy consumption. Additionally, utilities will minimize their carbon emissions, offering a better trading market [28].

\subsubsection{Smart renewable energy resources}

The integration between local generating renewable resources moves the end-user from customer to supplier during each operating cycle. This broadens the range of potential power demand/output values [27]. Renewable energy resources provide electricity at a lower cost with low carbon emissions [29]. It can be addressed through:

The Photovoltaic system is of the most promising electricity-producing innovations [30]. Wind Energy can feed the central grid or be consumed locally using small standalone wind turbines [31]. Geothermal Energy is mainly used to heat buildings [29]. Bioenergy (biomass) can exist in heat and electricity [32]. Smart generating solutions boost sustainability. It has a better environmental impact by lowering global warming and improving public health. As it is not depleted energy, it has an affordable and stable price. Moreover, it is reliable, resilient, and less likely to fail at a large scale.

\subsection{Smart Energy Consumption Systems (SECSs)}

The culture of energy conservation is weak in Egypt; this gives the SECSs its importance. In this scope, lighting and air-conditioning systems are the most energy-consuming systems in buildings, as follows:

\subsubsection{Smart Lighting systems}

Plug and lighting loads consume $12-50 \%$ of building energy collectively on average, and it rises at a rate of $0.8 \%$ annually [33]. LED lamps are added to the list of energy-efficient light sources. Its fixtures can use $75-80 \%$ less energy than incandescent bulbs, and it can last 25 times longer [34]. LED lighting system achieves energy savings by $44 \%$ compared to the fluorescent system [19].

The efficient control of smart indoor lighting systems is non-linear and time-variant, and it depends on a web-enabled and integrated server [35]. A WinLight app. was proposed to enable occupants to control lighting due to their preferences. Its experimental results have demonstrated that it has achieved energy savings of between $93.09 \%-80.27 \%$ compared to the fixed scheduled lighting control scheme and PIR sensor-based lighting control scheme, thus maintaining the comfort of the lighting allocated to the occupant. [20].

\subsubsection{Smart HVAC systems}

The smart HVAC Systems help energy and operational cost-saving, making maintenance more efficient. Moreover, it is possible to retrofit old buildings for Smart HVAC Systems [36]. It significantly affects the end user's virtual behavior by its new control architectures that energy optimization without neglecting occupants' thermal comfort. Furthermore, it provides policymakers and end-users with an interactive tool to monitor and control the HVAC system [22]. In the field, several and terminal 
devices are used to collect and control system data. Sensor controllers use device input and data to decide and then monitor actuator devices based on input information as thermostats, sensors, etc. [37].

\section{Case studies: Analyzing the SESs in SBs}

This article analyzes some case studies to touch SESs features that enhance energy efficiency to root sustainability in its broadest sense, and selecting them based on technologies to adapt their ideas to suit the Egyptian context and enduser needs.

\subsection{Sample selection criteria}

Selected samples are subjected to the following criteria:

a. Number of samples: The article analyzed 12 different international samples, two in the Arabic context and two in Egypt, to cover the SESs features in many environments and various technical levels.

b. Location of samples: It was chosen in different technical, civilized, and cultural levels to check the existence of SESs components, according to what already appears in the theoretical sections.

c. The sample's country's perspective regarding SBs: It covered the perspectives of the USA, Europe, and Asia, besides Arabian and Egyptian samples to define the manifestations of smartness in different contexts; besides, it gives an initial view of the Egyptian situation from this perspective.

d. Date of construction: to give a historical overview of its existence sequence in various contexts internationally.

e. Sample reputation: through achieving energy goals, winning awards, or being famous in this field.

\subsection{Conducting the case studies}

These case studies address SBs, which have adopted from the beginning the SESs concepts to reflect different conditions internationally. The study simplified the analysis through an inventory of the energy systems' smartness features as addressed in the theoretical part into SEMS, SEGSs, and SECSs, as shown in Table 1.

Table 1: The three key SESs' categories

$$
\begin{array}{cccc}
\boldsymbol{v}=\text { Exist } & \boldsymbol{x}=\text { Not Exist } \\
\mathrm{M} / \mathrm{Au}=\text { Manual }+ \text { Automatic } & \mathrm{A}=\underset{\text { Active }}{\mathrm{P} / \mathrm{A}=\text { Passive }+ \text { Active }} \quad \mathrm{M}=\text { Manual } & \mathrm{Au}=\text { Automatic }
\end{array}
$$

\begin{tabular}{|c|c|c|c|c|c|c|c|c|c|c|c|c|c|c|c|c|c|}
\hline \multirow{3}{*}{ 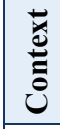 } & \multirow{3}{*}{$\begin{array}{l}\text { Case studies } \\
\text { (Locations) }\end{array}$} & \multicolumn{16}{|c|}{ Smart energy three key systems' categories } \\
\hline & & \multicolumn{8}{|c|}{ SEMS } & \multicolumn{2}{|c|}{ SEGSs } & \multicolumn{6}{|c|}{ SECSs } \\
\hline & & \multicolumn{3}{|c|}{ Lf Wd Oo } & Ge & \multirow{2}{*}{\begin{tabular}{|c|} 
Ralc \\
A
\end{tabular}} & HVACc & \multirow{2}{*}{$\frac{F c}{x}$} & \multirow{2}{*}{\begin{tabular}{|c} 
D \\
$A$
\end{tabular}} & \multirow{2}{*}{\begin{tabular}{c|c} 
a & SG \\
& $\checkmark$
\end{tabular}} & \multirow{3}{*}{$\frac{\mathbf{R R s}}{x}$} & \multicolumn{2}{|c|}{ RL DL } & \multicolumn{3}{|c|}{ Nv HVACs 1} & \multirow{3}{*}{$\frac{\text { Swh }}{\square \checkmark}$} \\
\hline & 151 North Franklin building, & $\checkmark$ & $\checkmark$ & $\checkmark$ & $\mathrm{A}$ & & A & & & & & $\checkmark$ & $\checkmark$ & $\checkmark$ & $\checkmark$ & \multirow{2}{*}{$\checkmark$} & \\
\hline \multirow[t]{3}{*}{$\ll$} & Chicago, U.S.A. 2018 [38] & & & & 至 & $\stackrel{\Xi}{\Sigma}$ & $\underset{\Sigma}{\Sigma}$ & $x$ & $\underset{\Sigma}{Z}$ & & & & & & & & \\
\hline & Hearst Tower, New York, U.S.A. & $x$ & $\checkmark$ & $\checkmark$ & $\mathrm{P} / \mathrm{A}$ & $\mathrm{A}$ & $\mathrm{P} / \mathrm{A}$ & $\mathbf{x}$ & $\mathrm{P} / \mathrm{A}$ & $\checkmark$ & $\mathbf{x}$ & $\checkmark$ & $\checkmark$ & $\checkmark$ & $\checkmark$ & $\mathbf{x}$ & $x$ \\
\hline & 2006 [39] & & & & $\mathrm{Au}$ & $\mathrm{Au}$ & $\mathrm{Au}$ & $x$ & $\mathrm{Au}$ & & & & & & & & \\
\hline \multirow{11}{*}{ छ్ } & The Edge building, Amsterdam, & $\checkmark$ & $\checkmark$ & $\checkmark$ & A & A & $\mathrm{P} / \mathrm{A}$ & A & A & $\checkmark$ & $\checkmark$ & $\checkmark$ & $\checkmark$ & $\checkmark$ & $\checkmark$ & $\checkmark$ & $\checkmark$ \\
\hline & Netherlands. 2014 [40] & & & & $\underset{\Sigma}{Z}$ & $\underset{\Sigma}{\Sigma}$ & $\underset{\Sigma}{\Sigma}$ & $\underset{\Sigma}{\Sigma}$ & $\underset{\Sigma}{z}$ & & & & & & & & \\
\hline & Hegau Tower, Singen, Germany. & $x$ & $\checkmark$ & $\checkmark$ & A & A & $\mathrm{P} / \mathrm{A}$ & A & $\mathrm{P} / \mathrm{A}$ & $\checkmark$ & $x$ & $\checkmark$ & $\checkmark$ & $\checkmark$ & $\checkmark$ & $x$ & $x$ \\
\hline & 2008[ & & & & 胥 & $\stackrel{\Xi}{\Sigma}$ & $\stackrel{\Xi}{\Sigma}$ & $\stackrel{\Xi}{\Sigma}$ & $\mathrm{Au}$ & & & & & & & & \\
\hline & The GSW headquarters, Berlin, & $\mathbf{x}$ & $\checkmark$ & $\checkmark$ & A & A & $\mathrm{P} / \mathrm{A}$ & $\mathrm{P} / \mathrm{A}$ & A & $\checkmark$ & $x$ & $\checkmark$ & $\checkmark$ & $\checkmark$ & $\checkmark$ & $\checkmark$ & $x$ \\
\hline & Germany. 1999 [41] & & & & $\underset{\Sigma}{\Sigma}$ & $\stackrel{\sum}{\Sigma}$ & $\underset{\Sigma}{\Sigma}$ & $\sum_{\Sigma}^{Z}$ & $\underset{\Sigma}{\Sigma}$ & & & & & & & & \\
\hline & The Environmental Building (BRE), & $\mathbf{x}$ & $\checkmark$ & $\checkmark$ & $\mathrm{P} / \mathrm{A}$ & A & A & A & A & $\checkmark$ & $\checkmark$ & $\checkmark$ & $\checkmark$ & $\checkmark$ & $\checkmark$ & $\checkmark$ & $x$ \\
\hline & Garston, UK 1 & & & & $\stackrel{\sum}{\Sigma}$ & $\stackrel{\Xi}{\Sigma}$ & $\stackrel{\Xi}{\Sigma}$ & 胥 & $\underset{\Sigma}{\Sigma}$ & & & & & & & & \\
\hline & Helicon, London, UK. 1996 [41] & $x$ & $\checkmark$ & $\checkmark$ & $\mathrm{A}$ & A & A & A & A & $\checkmark$ & $x$ & $\checkmark$ & $\checkmark$ & $\checkmark$ & $\checkmark$ & $x$ & $\mathbf{x}$ \\
\hline & & & & & 导 & $\underset{\Sigma}{z}$ & $\underset{\Sigma}{\Sigma}$ & 齐 & 昰 & & & & & & & & \\
\hline & & $x$ & $x$ & $\checkmark$ & A & A & A & $x$ & $P$ & $\checkmark$ & $x$ & $\checkmark$ & $\checkmark$ & $\checkmark$ & $\checkmark$ & $\checkmark$ & $x$ \\
\hline
\end{tabular}




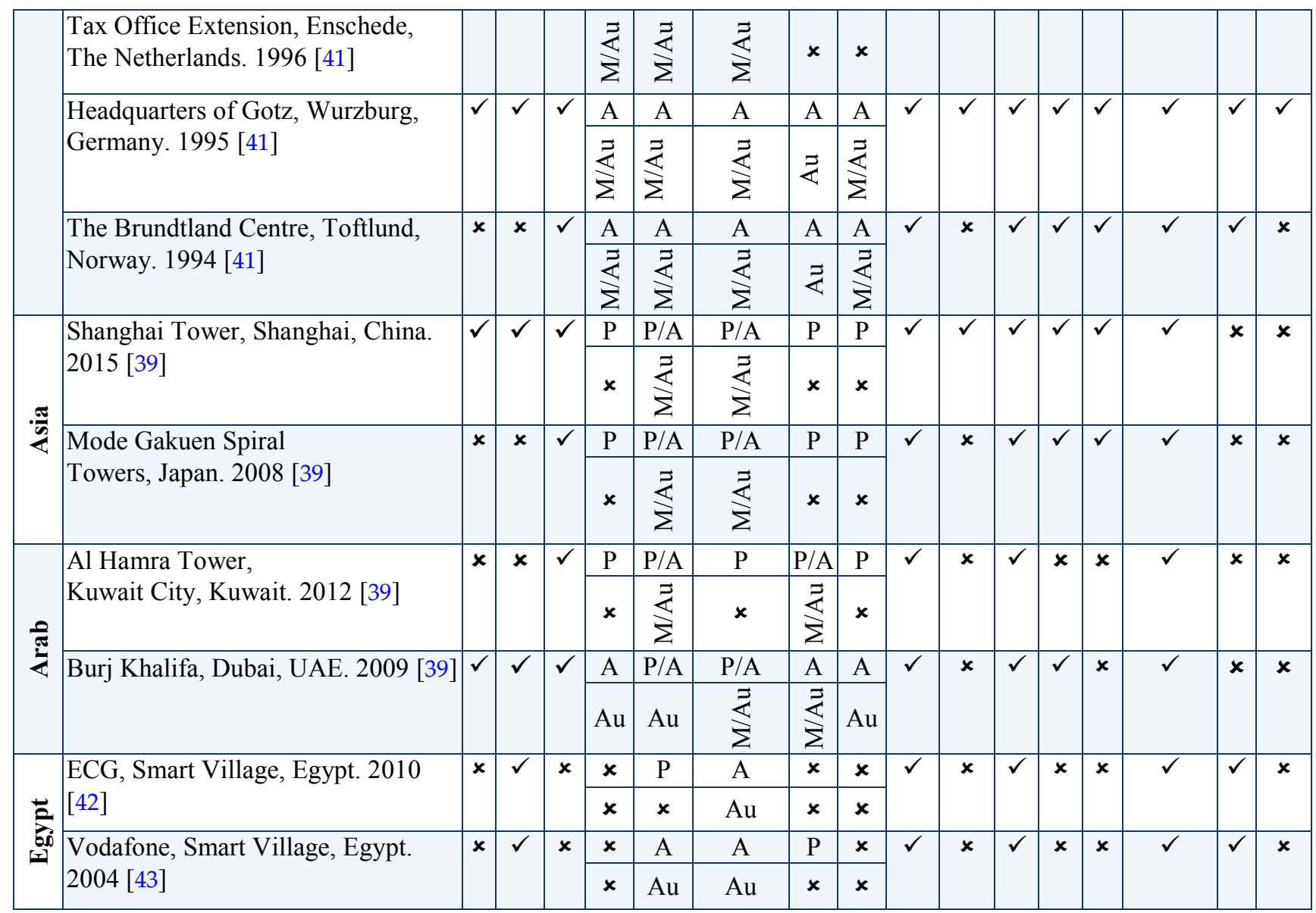

The essential features of SESs in buildings that proposed in Table 1 as initiatives to analyze these buildings, as follows:

\subsection{Analysis of the systems' three main categories included in the case studies}

The study enumerated key features of essential attributes regarding SESs as detailed in Table 1. The coming points will interpret symbols contained in that table and show its function through its three divisions, as follows:

a. SEMS: through eight key features, as follows:

(Lf) Learning facility: Its strategies are not common in SBs, especially before 2010, but it became vital to allow the SBs to keep the occupants' preferences. So, it helps SEMS to decide regarding energy efficiency controlling based on previous data.

(Wd) Weather data: SBs need to collect it with various sensors and measurement tools.

(Oo) Occupant override: A strategy facilitates desires and needs by overriding the automatic systems [10]. It is obeying the occupants' preferences granted its importance to all SBs regarding energy saving.
(Gc) Glare control blinds/ louvers: Most SBs have active Gc features controlled automatically by the SEMS or occupants.

(Ralc) Responsive artificial lighting control\& (HVACc) HVAC control: It significantly increases energy efficiency and controls consumption.

(Fc) Fabric control windows/ doors/ dampers\& (Da) Daylight reflection/protection adjustment: It controls heating, cooling, ventilation, and lighting process, depending on the available smartness.

b. SEGS: through two key features, as follows:

(SGs) Smart grids: Where smart IPs with sensors and other equipment overlay the electricity grid. It enhances the managing of the network, limits the electricity losses, prevents outages, etc.

(RRs) Renewable resources: It boosts sustainability as it is clean, reliable, and stable energy. Moreover, it reduces harmful emissions.

c. SECS: through six key features, as follows:

(RL) Responsive lights: It is high-efficiency lighting depending on motion sensors and body recognition.

(DL) Daylight\& (Nv) Natural ventilation: they are essential in SBs to exploit these free potentials 
needed for the operational process sustainably.

(HVACs): Depending on its provision with smart systems installations, it saves energy substantially, compared with conventional cases.

(c) Night cooling systems \& (Swh) Solar water heating: It depends on the building function, working hours, and climatic zones' changes, taking advantage of the potential of the environment smartly and promotes sustainability.

This article addresses the gap between the Egyptian perspective and the others in describing the Egyptian BMS's role, where it only controls and monitors the lighting and HVAC systems, which does not contain responsive control or make effective decisions. It passively affects Egypt's energy performance, as smart buildings increase energy efficiency by $30-40 \%$ than conventional [41]. This supports this article's hypothesis and aims. Moreover, it emphasizes that we need to adopt the concept of energy-efficiency in architectural practices in Egypt. It is a serious contemporary issue at the national level. It then comes up with a mechanism that helps the architectural field employees boost it in all stages, focusing on smart systems. So, the extracted proposed initiatives from both the theoretical and case studies firmly find their way to share in decreasing the gap recorded to boost national sustainability.

\section{Developing initiatives for boosting SESs in the Egyptian context}

This article developed 35 initiatives after investigating the Egyptian situation by summarizing the essential manifestations of SESs in Table 2 through justification, impact, priority, and availability to support this new trend in Egypt. The study identified descriptive and average cost based on the survey with the 2020 general inspection of the global market prices based on the products datasheets. Although priorities and costs vary depending on the project site, the table will help in decision making based on technical and financial facilities for energy preferences; this will be subjected to the consultant selectivity during projects preparation for its tender documents.

Table 2: Listing the proposed SESs initiatives

(Hi) High $\quad(\mathrm{Me})$ Medium $\quad($ Lo) Low $\quad(\checkmark)$ Exist $\quad(\mathbf{x})$ Not Exist $\quad$ (a) Affect directly $\quad$ (n) Affect indirectly (Ru) Resource utilization (Es) Energy savings (Id) Informed decision (Is) Improved services (Rm) Risk mitigation

\begin{tabular}{|c|c|c|c|c|c|c|c|c|c|c|}
\hline \multirow[t]{2}{*}{ Classifications } & \multirow[t]{2}{*}{ Smart energy systems' initiatives } & \multicolumn{5}{|c|}{ Justification/Impact } & \multirow[t]{2}{*}{ Pr } & \multirow[t]{2}{*}{$\mathbf{C}$} & \multicolumn{2}{|c|}{ Availability } \\
\hline & & $\vec{\not}$ & w & 므 & $\cong$ & $\tilde{\Xi}$ & & & 焉 & 定 \\
\hline \multirow{17}{*}{$\sum_{\infty=1}^{\infty}$} & 1. Collecting information about the existence of indoors occupants & $\mathrm{a}$ & $\mathrm{a}$ & $\mathrm{n}$ & $\mathrm{n}$ & $\mathrm{n}$ & $\mathrm{Hi}$ & $\mathrm{Me}$ & $\checkmark$ & $\checkmark$ \\
\hline & 2. Collecting indoor and outdoor environmental data by using sensors & $\mathrm{a}$ & $\mathrm{a}$ & $\mathrm{n}$ & $\mathrm{n}$ & $\mathrm{n}$ & $\mathrm{Hi}$ & $\mathrm{Me}$ & $\checkmark$ & $\checkmark$ \\
\hline & 3. Interaction between units of industrial lighting and SEMS & $\mathrm{n}$ & $\mathrm{a}$ & $\mathrm{n}$ & a & $\mathrm{n}$ & $\mathrm{Hi}$ & $\mathrm{Me}$ & $x$ & $\checkmark$ \\
\hline & 4. Enabling the interaction between the HVAC system and the SEMS & $\mathrm{n}$ & $\mathrm{a}$ & $\mathrm{n}$ & $\mathrm{a}$ & $\mathrm{n}$ & $\mathrm{Hi}$ & $\mathrm{Me}$ & $x$ & $\checkmark$ \\
\hline & 5. Adjusting the maintenance rates of the lighting system & $\mathrm{n}$ & $\mathrm{a}$ & $\mathrm{n}$ & $\mathrm{a}$ & $\mathrm{a}$ & $\mathrm{Hi}$ & $\mathrm{Me}$ & $x$ & $\checkmark$ \\
\hline & 6. Adjusting the maintenance rates of the HVAC system & $\mathrm{n}$ & $\mathrm{a}$ & $\mathrm{n}$ & $\mathrm{a}$ & a & $\mathrm{Hi}$ & $\mathrm{Me}$ & $x$ & $\checkmark$ \\
\hline & 7. Adoption of high-speed internet & $\mathrm{n}$ & $\mathrm{n}$ & $\mathrm{a}$ & $\mathrm{a}$ & $\mathrm{n}$ & $\mathrm{Hi}$ & $\mathrm{Me}$ & $\checkmark$ & $\checkmark$ \\
\hline & $\begin{array}{l}\text { 8. Using systems with long operational lifespan with low operating } \\
\text { costs }\end{array}$ & $\mathrm{n}$ & $\mathrm{a}$ & $\mathrm{n}$ & $\mathrm{n}$ & a & $\mathrm{Hi}$ & $\mathrm{Hi}$ & $\checkmark$ & $\checkmark$ \\
\hline & $\begin{array}{l}\text { 9. Developing building management systems (BMS) and smart energy } \\
\text { management systems (SEMS) }\end{array}$ & $\mathrm{n}$ & $\mathrm{a}$ & $\mathrm{a}$ & $\mathrm{n}$ & $\mathrm{n}$ & $\mathrm{Hi}$ & $\mathrm{Hi}$ & $\checkmark$ & $\checkmark$ \\
\hline & 10. Spaces reports based on counted people & $\mathrm{a}$ & $\mathrm{a}$ & $\mathrm{n}$ & $\mathrm{n}$ & $\mathrm{n}$ & $\mathrm{Me}$ & Lo & $x$ & $\checkmark$ \\
\hline & $\begin{array}{l}\text { 11. Using digital control where each separate space or system has an } \\
\text { IP address }\end{array}$ & $\mathrm{n}$ & $\mathrm{n}$ & $\mathrm{n}$ & $\mathrm{a}$ & $\mathrm{n}$ & $\mathrm{Me}$ & $\mathrm{Me}$ & $\checkmark$ & $\checkmark$ \\
\hline & 12. Connecting ESs through the ethernet networks & $\mathrm{n}$ & $\mathrm{n}$ & $\mathrm{n}$ & $\mathrm{a}$ & $\mathrm{n}$ & $\mathrm{Me}$ & $\mathrm{Me}$ & $\checkmark$ & $x$ \\
\hline & 13. Setting interfaced SEMS with net-zero energy consumption & $\mathrm{n}$ & $\mathrm{a}$ & $\mathrm{n}$ & $\mathrm{a}$ & $\mathrm{n}$ & $\mathrm{Me}$ & $\mathrm{Me}$ & $\checkmark$ & $\checkmark$ \\
\hline & 14. Promoting the concept of the internet of things (IoT) & $\mathrm{n}$ & $\mathrm{n}$ & $\mathrm{n}$ & $\mathrm{a}$ & $\mathrm{n}$ & $\mathrm{Me}$ & $\mathrm{Me}$ & $x$ & $\checkmark$ \\
\hline & 15. Using wireless technologies and cloud storage & $\mathrm{n}$ & $\mathrm{n}$ & $\mathrm{n}$ & $\mathrm{a}$ & $\mathrm{n}$ & $\mathrm{Me}$ & $\mathrm{Me}$ & $\checkmark$ & $\checkmark$ \\
\hline & $\begin{array}{l}\text { 16. Recurrence of the system breakdown (testing of the system } \\
\text { collapse) }\end{array}$ & $\mathrm{n}$ & $\mathrm{n}$ & $\mathrm{n}$ & $\mathrm{n}$ & a & $\mathrm{Me}$ & $\mathrm{Me}$ & $x$ & $\checkmark$ \\
\hline & 17. Availability of integrated, Interactive, and smart spaces & $\mathrm{n}$ & $\mathrm{a}$ & $\mathrm{a}$ & $\mathrm{a}$ & $\mathrm{n}$ & $\mathrm{Me}$ & $\mathrm{Hi}$ & $x$ & $x$ \\
\hline
\end{tabular}




\begin{tabular}{|c|c|c|c|c|c|c|c|c|c|c|c|}
\hline & $\begin{array}{l}\text { 18. Displaying QR codes on the walls that can be scanned for } \\
\text { information about the location, mapping, schedules, and } \\
\text { controlling the energy systems }\end{array}$ & a & $\mathrm{a}$ & $\mathrm{n}$ & $\mathrm{n}$ & $\mathrm{n}$ & Lo & Lo & $\checkmark$ & $\checkmark$ \\
\hline & & $\begin{array}{l}\text { 19. Scanning free spaces and free chairs indoors, i.e., classrooms, } \\
\text { study halls, offices, etc. that provide data for both the } \\
\text { energy management systems and managers }\end{array}$ & $\mathrm{n}$ & a & $\mathrm{n}$ & $\mathrm{a}$ & $\mathrm{n}$ & Lo & $\mathrm{Me}$ & $\checkmark$ & $\checkmark$ \\
\hline & & $\begin{array}{l}\text { 20. Applying face recognition technology for different spaces for } \\
\text { attendance and behavior monitoring }\end{array}$ & $\mathrm{n}$ & a & $\mathrm{n}$ & $n$ & $\mathrm{a}$ & Lo & $\mathrm{Me}$ & $x$ & $\checkmark$ \\
\hline \multirow{2}{*}{\multicolumn{2}{|c|}{ SEGSs }} & 21. Adopting renewable resources as sustainable & a & $\mathrm{a}$ & $\mathrm{n}$ & $\mathrm{n}$ & $\mathrm{n}$ & $\mathrm{Me}$ & $\mathrm{Hi}$ & $\checkmark$ & $\checkmark$ \\
\hline & & 22. Applying smart grids & $\mathrm{n}$ & a & $\mathrm{n}$ & $\mathrm{n}$ & $\mathrm{n}$ & $\mathrm{Me}$ & $\mathrm{Hi}$ & $\checkmark$ & $\checkmark$ \\
\hline \multirow{13}{*}{$\sum_{\substack{\infty \\
\infty}}^{\infty}$} & \multirow{8}{*}{$\ddot{\mathscr{n}}$} & 23. Enabling occupants to override automation mode & $\mathrm{n}$ & $\mathrm{a}$ & $\mathrm{n}$ & $\mathrm{a}$ & $\mathrm{n}$ & $\mathrm{Hi}$ & Lo & $\checkmark$ & $\checkmark$ \\
\hline & & 24. Using smart lighting units and LEDs & $\mathrm{a}$ & a & $\mathrm{n}$ & $\mathrm{a}$ & $\mathrm{n}$ & $\mathrm{Hi}$ & $\mathrm{Me}$ & $\checkmark$ & $\checkmark$ \\
\hline & & 25. Establishing and equipping an emergency lighting network & a & $\mathrm{n}$ & $\mathrm{n}$ & $\mathrm{a}$ & $\mathrm{n}$ & $\mathrm{Hi}$ & $\mathrm{Me}$ & $\checkmark$ & $\checkmark$ \\
\hline & & $\begin{array}{l}\text { 26. Promote integration between daylight and artificial lighting units } \\
\text { to take advantage of natural resources sustainably }\end{array}$ & $\mathrm{N}$ & a & $\mathrm{n}$ & $\mathrm{n}$ & $\mathrm{n}$ & $\mathrm{Me}$ & Lo & $x$ & $\checkmark$ \\
\hline & & 27. The widespread use of smart lighting control systems & $\mathrm{n}$ & a & a & $\mathrm{n}$ & $\mathrm{n}$ & $\mathrm{Me}$ & $\mathrm{Me}$ & $\checkmark$ & $\checkmark$ \\
\hline & & 28. Utilizing the smart LED dimming systems & $\mathrm{a}$ & $\mathrm{a}$ & $\mathrm{n}$ & $\mathrm{a}$ & $\mathrm{n}$ & $\mathrm{Me}$ & $\mathrm{Me}$ & $\checkmark$ & $\checkmark$ \\
\hline & & $\begin{array}{l}\text { 29. Measuring the efficiency of lighting units and maximizing } \\
\text { consumption rationalization mechanisms }\end{array}$ & $\mathrm{n}$ & $\mathrm{n}$ & $\mathrm{n}$ & $\mathrm{a}$ & $\mathrm{a}$ & $\mathrm{Me}$ & $\mathrm{Me}$ & $\checkmark$ & $\checkmark$ \\
\hline & & 30. Setting the fingerprint lighting management system & $\mathrm{n}$ & a & $\mathrm{a}$ & $\mathrm{a}$ & $\mathrm{n}$ & $\mathrm{Me}$ & $\mathrm{Hi}$ & $x$ & $\checkmark$ \\
\hline & \multirow{5}{*}{ 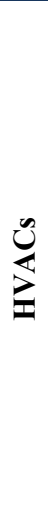 } & $\begin{array}{l}\text { 31. Using the smart control to make sure the indoor environmental } \\
\text { quality regarding air, smoke, energy-reduction, temperature } \\
\text { sensing, air velocity, humidity, and occupants motion sensing }\end{array}$ & $\mathrm{n}$ & a & $\mathrm{a}$ & $\mathrm{n}$ & $\mathrm{n}$ & $\mathrm{Hi}$ & $\mathrm{Me}$ & $\checkmark$ & $\checkmark$ \\
\hline & & $\begin{array}{l}\text { 32. Use smart control in HVAC systems by considering the electricity } \\
\text { consumption rates in them and the price of the power unit in terms } \\
\text { of its classification as commercial use }\end{array}$ & $\mathrm{n}$ & $\mathrm{a}$ & $\mathrm{a}$ & $\mathrm{n}$ & $\mathrm{n}$ & $\mathrm{Hi}$ & $\mathrm{Me}$ & $x$ & $\checkmark$ \\
\hline & & $\begin{array}{l}\text { 33. Promote integration between ventilation and the HVAC systems } \\
\text { to take advantage of natural resources, enhancing sustainability }\end{array}$ & $\mathrm{a}$ & $\mathrm{a}$ & $\mathrm{n}$ & $\mathrm{n}$ & $\mathrm{n}$ & $\mathrm{Me}$ & Lo & $\checkmark$ & $\checkmark$ \\
\hline & & $\begin{array}{l}\text { 34. Providing the requirements for controlling the indoors' health } \\
\text { dimension, including measuring the fresh air change's rate }\end{array}$ & $\mathrm{n}$ & $\mathrm{n}$ & $\mathrm{n}$ & $\mathrm{a}$ & $\mathrm{a}$ & $\mathrm{Me}$ & Lo & $\checkmark$ & $\checkmark$ \\
\hline & & $\begin{array}{l}\text { 35. The systems can override control and automation systems in } \\
\text { HVAC systems as an option when necessary }\end{array}$ & $\mathrm{n}$ & $\mathrm{a}$ & $\mathrm{n}$ & $\mathrm{a}$ & $\mathrm{n}$ & $\mathrm{Me}$ & $\mathrm{Me}$ & $x$ & $\checkmark$ \\
\hline
\end{tabular}

The initiatives that appeared in Table 2 represent this article's actual outputs related to SESs, which keep the same division addressed in the theoretical section. The article set three categories to give a unified vision for the architect to support his new trend. These categories contain symbols, which divided into six columns dealing with the initiatives through the following abbreviations:

a. Classifications: It contains the three divisions of SESs, which are SEMS, SEGSs, and SECSs.

b. Smart Energy Systems' Initiatives: It is 35 and divided according to the classifications.

c. Justification/Impact: It comes through five axes; these are:

- $(\mathrm{Ru})$ Resource utilization: How the application affects the resources to maximize performance?

- (Es) Energy savings: It refers to the effect of the application in the energy sector.
- (Id) Informed decision: How the application directly affects decision-making in systems?

- (IS) Improved services: How the application affects systems to maximize performance?

- (Rm) Risk mitigation: How the application helps directly minimize threats in data?

d. (Pr) Priority: Analyzing case studies addressed in Table 1 by dividing it into three divisions: high, medium, and low.

e. (C) Cost: It means the average cost depending on the product's datasheets, and it is divided into high, medium, and low.

f. (Av) Availability: Through the next two axes:

- (Hw) Hardware: It refers to the physical components.

- (Sw) Software: It refers to a set of instructions that enable users to interact with systems or give the system the instructions of what to do. 


\section{Checking the developed initiatives in the Egyptian context}

The study considers the data set in Table 2 as a tool contributing to establishing similar data as abbreviated in Table 3 to examine three types of data regarding the availability, existence, and efficiency. Ten samples were conducted in the smart village to verify these initiatives in Egypt through the survey's checklist filled out by staff and technicians. The samples' numbers were reduced to five, considering smartness features. The chosen samples are ECG (Engineering Consultants Group), Orange (Telecommunications Corporation), HSBC (bank), Oracle Egypt (Multinational computer technology corporation), and Huawei (Chinese multinational technology company).

The survey aims to show the gap between the proposed initiatives of SESs and their counterparts in the Egyptian context. The study reflects the concluded concepts and details to formularize a tool to examine the existing buildings using the prepared
Table 3 that contains the following categories:

a. Classifications: It contains the three divisions of SESs: SEMS, SEGSs, and SECSs.

b. Initiatives of SESs: The deducted 35 initiatives.

c. Availability: It shows the market status regarding the application/ initiative. Its possibilities are:

- (Av0): Not available

- (Av1): Available

- (Av2): Available in abundance

d. Existence: It refers to the existence of the initiative or not.

e. Efficiency: It refers to the performance of the existing initiative, which comes through three axes; these are:

- (B) Bad: The weakness of the efficiency.

- (M) Moderate: The efficiency is average.

- (G) Good: It shows an effective, beneficial, and robust performance.

- (NA) Not applicable: It means that the initiative is not achieved/exist.

Table 3: Checking what was achieved from the proposed 35 initiatives of SESs in the Egyptian context

\begin{tabular}{|c|c|c|c|c|c|c|c|c|c|c|}
\hline \multirow[t]{2}{*}{ Classifications } & \multirow{2}{*}{$\begin{array}{l}\text { The proposed } 35 \text { initiatives of SESs in the } \\
\text { Egyptian scope }\end{array}$} & \multirow{2}{*}{$\begin{array}{c}\text { Priority } \\
\text { (Pr) }\end{array}$} & \multicolumn{3}{|c|}{ Availability } & \multirow{2}{*}{$\begin{array}{c}\text { Sample } \\
\text { name }\end{array}$} & \multirow[t]{2}{*}{ Exist } & \multicolumn{3}{|c|}{ Efficiency } \\
\hline & & & Av0 & Av1 & Av2 & & & B & $\mathbf{M}$ & G \\
\hline \multirow{29}{*}{$\sum_{\substack{n=1 \\
\infty}}^{\infty}$} & \multirow{5}{*}{$\begin{array}{l}\text { 1. Collecting information about the existence of } \\
\text { indoors occupants }\end{array}$} & \multirow[t]{5}{*}{$\mathrm{Hi}$} & & & \multirow[t]{5}{*}{$\checkmark$} & ECG & $\checkmark$ & & & $\checkmark$ \\
\hline & & & & & & Orange & $\checkmark$ & & $\checkmark$ & \\
\hline & & & & & & HSBC & $\checkmark$ & & & $\checkmark$ \\
\hline & & & & & & Oracle & $\checkmark$ & & $\checkmark$ & \\
\hline & & & & & & Huawei & $\checkmark$ & & & $\checkmark$ \\
\hline & \multirow{5}{*}{$\begin{array}{l}\text { 2. Collecting indoor and outdoor environmental } \\
\text { data by using sensors }\end{array}$} & \multirow[t]{5}{*}{$\mathrm{Hi}$} & & & \multirow[t]{5}{*}{$\checkmark$} & ECG & $\checkmark$ & & $\checkmark$ & \\
\hline & & & & & & Orange & $\checkmark$ & & $\checkmark$ & \\
\hline & & & & & & HSBC & $\checkmark$ & & $\checkmark$ & \\
\hline & & & & & & Oracle & $\checkmark$ & & $\checkmark$ & \\
\hline & & & & & & Huawei & $\begin{array}{lll}\checkmark & & \\
\end{array}$ & & $\checkmark$ & \\
\hline & \multirow{5}{*}{$\begin{array}{l}\text { 3. Interaction between units of industrial lighting } \\
\text { and SEMS }\end{array}$} & \multirow[t]{5}{*}{$\mathrm{Hi}$} & & & \multirow[t]{5}{*}{$\checkmark$} & ECG & $x$ & \multicolumn{3}{|c|}{ NA } \\
\hline & & & & & & Orange & $\checkmark$ & & & $\checkmark$ \\
\hline & & & & & & HSBC & $\checkmark$ & & & $\checkmark$ \\
\hline & & & & & & Oracle & $x$ & \multicolumn{3}{|c|}{ NA } \\
\hline & & & & & & Huawei & $x$ & & NA & \\
\hline & \multirow{5}{*}{$\begin{array}{l}\text { 4. Enabling the interaction between the HVAC } \\
\text { system and the SEMS }\end{array}$} & \multirow[t]{5}{*}{$\mathrm{Hi}$} & & & \multirow[t]{5}{*}{$\checkmark$} & ECG & $\checkmark$ & & & $\checkmark$ \\
\hline & & & & & & Orange & $\checkmark$ & & & $\checkmark$ \\
\hline & & & & & & HSBC & $\checkmark$ & & & $\checkmark$ \\
\hline & & & & & & Oracle & $\checkmark$ & & & $\checkmark$ \\
\hline & & & & & & Huawei & $\checkmark$ & & $\checkmark \checkmark$ & \\
\hline & \multirow{5}{*}{$\begin{array}{l}\text { 5. Adjusting the maintenance rates of the lighting } \\
\text { system }\end{array}$} & \multirow[t]{5}{*}{$\mathrm{Hi}$} & & & \multirow[t]{5}{*}{$\checkmark$} & ECG & $\checkmark$ & & & $\checkmark$ \\
\hline & & & & & & Orange & $\checkmark$ & & & $\checkmark$ \\
\hline & & & & & & HSBC & $\checkmark$ & & & $\checkmark$ \\
\hline & & & & & & \begin{tabular}{|l|} 
Oracle \\
\end{tabular} & $\checkmark$ & & & $\checkmark$ \\
\hline & & & & & & Huawei & $\checkmark$ & & & $\checkmark$ \\
\hline & \multirow{4}{*}{$\begin{array}{l}\text { 6. Adjusting the maintenance rates of the HVAC } \\
\text { system }\end{array}$} & \multirow[t]{4}{*}{$\mathrm{Hi}$} & & & \multirow[t]{4}{*}{$\checkmark$} & ECG & $\checkmark$ & & & $\checkmark$ \\
\hline & & & & & & Orange & $\checkmark$ & & & $\checkmark$ \\
\hline & & & & & & HSBC & $\checkmark$ & & & $\checkmark$ \\
\hline & & & & & & Oracle & $\checkmark$ & & $\checkmark$ & \\
\hline
\end{tabular}




\begin{tabular}{|c|c|c|c|c|c|c|c|c|c|}
\hline & & & & & Huawei & $\checkmark$ & & & $\checkmark$ \\
\hline \multirow[t]{5}{*}{ 7. Adoption of high-speed internet } & \multirow[t]{5}{*}{$\mathrm{Hi}$} & & \multirow[t]{5}{*}{$\checkmark$} & & ECG & $\checkmark$ & & & $\checkmark$ \\
\hline & & & & & Orange & $\checkmark$ & & & $\checkmark$ \\
\hline & & & & & HSBC & $\checkmark$ & & & $\checkmark$ \\
\hline & & & & & Oracle & $\checkmark$ & & & $\checkmark$ \\
\hline & & & & & Huawei & $\checkmark$ & & & $\checkmark$ \\
\hline \multirow{5}{*}{$\begin{array}{l}\text { 8. Using systems with long operational lifespan } \\
\text { with low operating costs }\end{array}$} & \multirow[t]{5}{*}{$\mathrm{Hi}$} & & & $\checkmark$ & ECG & $\checkmark$ & & & $\checkmark$ \\
\hline & & & & & Orange & $\checkmark$ & & & $\checkmark$ \\
\hline & & & & & HSBC & $\checkmark$ & & & $\checkmark$ \\
\hline & & & & & Oracle & $\checkmark$ & & & $\checkmark$ \\
\hline & & & & & Huawei & $\checkmark$ & & & $\checkmark$ \\
\hline \multirow{5}{*}{$\begin{array}{l}\text { 9. Developing building management systems } \\
\text { (BMS) and smart energy management systems } \\
\text { (SEMS) }\end{array}$} & \multirow[t]{5}{*}{$\mathrm{Hi}$} & & & $\checkmark$ & ECG & $\checkmark$ & & & $\checkmark$ \\
\hline & & & & & Orange & $\checkmark$ & & & $\checkmark$ \\
\hline & & & & & HSBC & $\checkmark$ & & $\checkmark$ & \\
\hline & & & & & Oracle & $\checkmark$ & $\checkmark$ & & \\
\hline & & & & & Huawei & $\checkmark$ & & $\checkmark$ & \\
\hline \multirow[t]{5}{*}{ 10. Spaces reports based on counted people } & \multirow[t]{5}{*}{$\mathrm{Me}$} & & & \multirow[t]{5}{*}{$\checkmark$} & ECG & $\checkmark$ & & $\checkmark$ & \\
\hline & & & & & Orange & $\checkmark$ & & $\checkmark$ & \\
\hline & & & & & HSBC & $\checkmark$ & & & $\checkmark$ \\
\hline & & & & & Oracle & $\checkmark$ & & & $\checkmark$ \\
\hline & & & & & Huawei & $\checkmark$ & & & $\checkmark$ \\
\hline \multirow{5}{*}{$\begin{array}{l}\text { 11. Using digital control where each separate } \\
\text { space or system has an IP address }\end{array}$} & \multirow[t]{5}{*}{$\mathrm{Me}$} & \multirow[t]{5}{*}{$x$} & & & ECG & $x$ & \multicolumn{3}{|c|}{ NA } \\
\hline & & & & & Orange & $x$ & \multirow{2}{*}{\multicolumn{3}{|c|}{$\begin{array}{l}\text { NA } \\
\text { NA }\end{array}$}} \\
\hline & & & & & HSBC & $x$ & & & \\
\hline & & & & & Oracle & $x$ & & NA & \\
\hline & & & & & Huawei & $x$ & & NA & \\
\hline 12. Connecting ESs through the ethernet & $\mathrm{Me}$ & $x$ & & & ECG & $x$ & & NA & \\
\hline networks & & & & & Orange & $x$ & & NA & \\
\hline & & & & & HSBC & $x$ & & NA & \\
\hline & & & & & Oracle & $x$ & & NA & \\
\hline & & & & & Huawei & $x$ & & NA & \\
\hline 13. Setting interfaced SEMS with net-zero energy & $\mathrm{Me}$ & $x$ & & & ECG & $x$ & & NA & \\
\hline consumption & & & & & Orange & $x$ & & NA & \\
\hline & & & & & HSBC & $x$ & & NA & \\
\hline & & & & & Oracle & $x$ & & NA & \\
\hline & & & & & Huawei & $x$ & & NA & \\
\hline 14. Promoting the concept of the internet of & $\mathrm{Me}$ & $x$ & & & ECG & $x$ & & NA & \\
\hline things (IoT) & & & & & Orange & $x$ & & NA & \\
\hline & & & & & HSBC & $x$ & & NA & \\
\hline & & & & & Oracle & $x$ & & NA & \\
\hline & & & & & Huawei & $x$ & & NA & \\
\hline 15. Using wireless technologies and cloud & $\mathrm{Me}$ & $x$ & & & ECG & $x$ & & NA & \\
\hline storage & & & & & Orange & $x$ & & NA & \\
\hline & & & & & HSBC & $x$ & & NA & \\
\hline & & & & & Oracle & $x$ & & NA & \\
\hline & & & & & Huawei & $x$ & & NA & \\
\hline 16. Recurrence of the system breakdown (testing & $\mathrm{Me}$ & & $\checkmark$ & & ECG & $\checkmark$ & & & $\checkmark$ \\
\hline of the system collapse) & & & & & Orange & $\checkmark$ & & & $\checkmark$ \\
\hline & & & & & HSBC & $\checkmark$ & & & $\checkmark$ \\
\hline & & & & & Oracle & $\checkmark$ & & $\checkmark$ & \\
\hline & & & & & Huawei & $\checkmark$ & & & $\checkmark$ \\
\hline 17. Availability of integrated, Interactive, and & $\mathrm{Me}$ & $x$ & & & ECG & $x$ & & NA & \\
\hline smart spaces & & & & & Orange & $x$ & & NA & \\
\hline & & & & & HSBC & $x$ & & NA & \\
\hline & & & & & Oracle & $x$ & & NA & \\
\hline & & & & & Huawei & $x$ & & NA & \\
\hline 18. Displaying QR codes on the walls that can be & $\mathrm{Me}$ & $x$ & & & ECG & $x$ & & NA & \\
\hline scanned for information about the location, & & & & & Orange & $x$ & & NA & \\
\hline
\end{tabular}




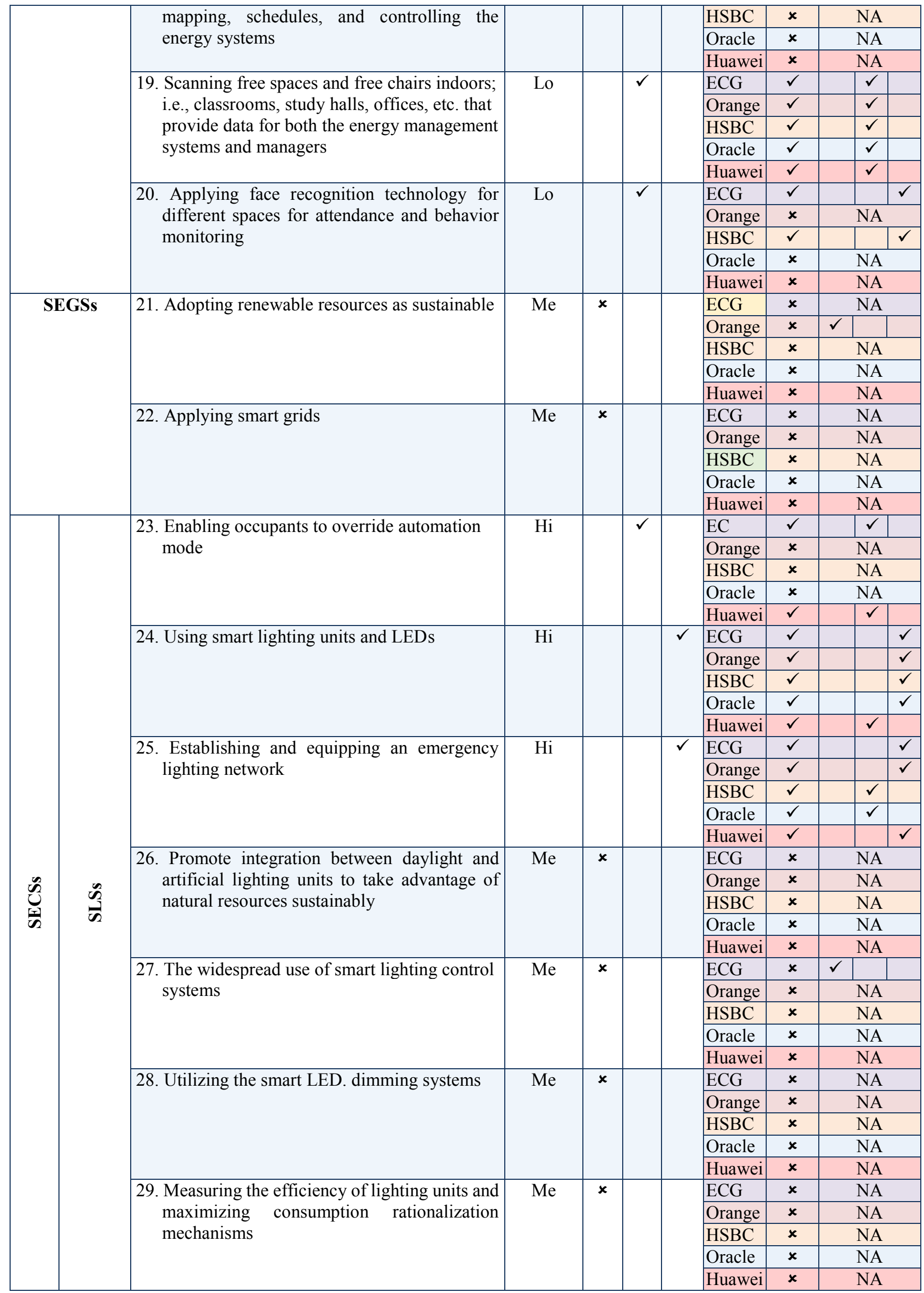




\begin{tabular}{|c|c|c|c|c|c|c|c|c|c|}
\hline & \multirow{5}{*}{$\begin{array}{l}\text { 30. Setting the fingerprint lighting management } \\
\text { system }\end{array}$} & \multirow[t]{5}{*}{$\mathrm{Me}$} & \multirow[t]{5}{*}{$x$} & & ECG & $x$ & \multirow{2}{*}{\multicolumn{3}{|c|}{$\frac{\text { NA }}{\text { NA }}$}} \\
\hline & & & & & Orange & $x$ & & & \\
\hline & & & & & HSBC & $x$ & $\checkmark$ & & \\
\hline & & & & & Oracle & $x$ & \multicolumn{3}{|c|}{ NA } \\
\hline & & & & & Huawei & $x$ & \multicolumn{3}{|c|}{ NA } \\
\hline \multirow{25}{*}{$\sum_{i}^{\infty}$} & \multirow{5}{*}{$\begin{array}{l}\text { 31. Using the smart control to make sure the } \\
\text { indoor environmental quality regarding } \\
\text { air, smoke, energy-reduction, temperature } \\
\text { sensing, air velocity, humidity, and } \\
\text { occupants motion sensing }\end{array}$} & \multirow[t]{5}{*}{$\mathrm{Hi}$} & & \multirow[t]{5}{*}{$\checkmark$} & ECG & $\checkmark$ & & & $\checkmark$ \\
\hline & & & & & Orange & $\checkmark$ & & & $\checkmark$ \\
\hline & & & & & HSBC & $\checkmark$ & & & $\checkmark$ \\
\hline & & & & & Oracle & $\checkmark$ & & & $\checkmark$ \\
\hline & & & & & Huawei & $\checkmark$ & & $\checkmark$ & \\
\hline & \multirow{5}{*}{$\begin{array}{l}\text { 32. Use smart control in HVAC systems by } \\
\text { considering the electricity consumption rates } \\
\text { in them and the price of the power unit in } \\
\text { terms of its classification as commercial use }\end{array}$} & \multirow[t]{5}{*}{$\mathrm{Hi}$} & & \multirow[t]{5}{*}{$\checkmark$} & ECG & $\checkmark$ & & $\checkmark$ & \\
\hline & & & & & Orange & $\checkmark$ & & & $\checkmark$ \\
\hline & & & & & HSBC & $\checkmark$ & & & $\checkmark$ \\
\hline & & & & & Oracle & $\checkmark$ & & & $\checkmark$ \\
\hline & & & & & Huawei & $\checkmark$ & & & $\checkmark$ \\
\hline & \multirow{5}{*}{$\begin{array}{l}\text { 33. Promote integration between ventilation and } \\
\text { the HVAC systems to take advantage of } \\
\text { natural resources, enhancing sustainability }\end{array}$} & \multirow[t]{5}{*}{$\mathrm{Me}$} & \multirow[t]{5}{*}{$x$} & & ECG & $x$ & \multicolumn{3}{|c|}{ NA } \\
\hline & & & & & Orange & $x$ & \multicolumn{3}{|c|}{ NA } \\
\hline & & & & & HSBC & $x$ & \multicolumn{3}{|c|}{ NA } \\
\hline & & & & & Oracle & $x$ & \multicolumn{3}{|c|}{ NA } \\
\hline & & & & & Huawei & $x$ & \multicolumn{3}{|c|}{ NA } \\
\hline & \multirow{5}{*}{$\begin{array}{l}\text { 34. Providing the requirements for controlling the } \\
\text { indoors health dimension, including } \\
\text { measuring the fresh air change's rate }\end{array}$} & \multirow[t]{5}{*}{$\mathrm{Me}$} & & \multirow[t]{5}{*}{$\checkmark$} & ECG & $\checkmark$ & & & $\checkmark$ \\
\hline & & & & & \begin{tabular}{|l|} 
Orange \\
\end{tabular} & $\checkmark$ & & & $\checkmark$ \\
\hline & & & & & HSBC & $\checkmark$ & & & $\checkmark$ \\
\hline & & & & & Oracle & $\checkmark$ & & $\checkmark$ & \\
\hline & & & & & Huawei & $\checkmark$ & & & $\checkmark$ \\
\hline & & \multirow[t]{5}{*}{$\mathrm{Me}$} & \multirow[t]{5}{*}{$x$} & & ECG & $x$ & \multicolumn{3}{|c|}{ NA } \\
\hline & & & & & Orange & $x$ & \multicolumn{3}{|c|}{ NA } \\
\hline & & & & & HSBC & $x$ & \multicolumn{3}{|c|}{ NA } \\
\hline & & & & & Oracle & $x$ & & $\mathrm{NA}$ & \\
\hline & & & & & Huawei & $x$ & & NA & \\
\hline
\end{tabular}

\section{Results}

This article developed 35 initiatives listed in Table 2; the applied section checked ten samples (reduced to five documented samples) as shown in Table 3 to check the existence and evaluate the achieved initiatives efficiencies in the Egyptian situation. The developed initiatives have been divided into three sections, as shown in Table 4.

Table 4: The achieved SESs initiatives in the samples

\begin{tabular}{|c|c|c|c|c|c|c|c|c|c|}
\hline \multicolumn{10}{|c|}{ SEMS } \\
\hline 1 & 2 & 3 & 4 & 5 & 6 & 7 & 8 & 9 & 10 \\
\hline 11 & 12 & 13 & 14 & 15 & 16 & 17 & 18 & 19 & 20 \\
\hline \multicolumn{10}{|c|}{ SEGs } \\
\hline 21 & 22 & & \multicolumn{10}{|c|}{} & & & & & \\
\hline \multicolumn{10}{|c|}{ SECSs } \\
\hline 23 & 24 & 25 & 26 & 27 & 28 & 29 & 30 & 31 & 32 \\
\hline 33 & 34 & 35 & & & & & & & \\
\hline
\end{tabular}

The achieved initiatives in all sections are 22, representing $22 / 35=62.86 \%$. Moreover, its average count $=17.6$ initiatives, representing $50.28 \%$ of the total recorded samples' initiatives, as shown in Fig. 4.

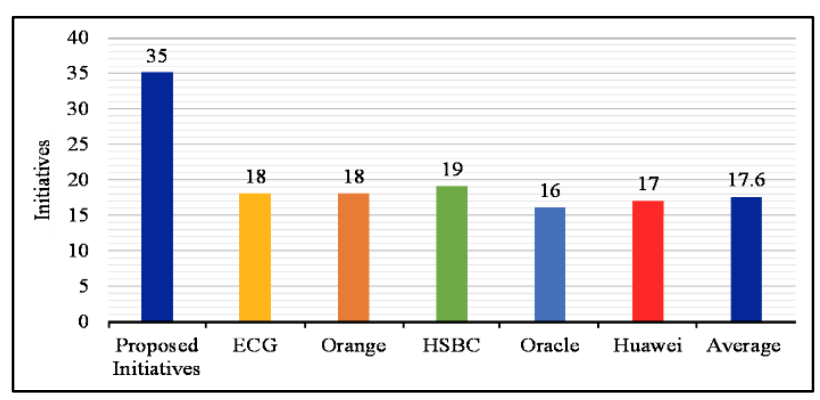

Fig. 4: The SESs achieved initiatives in the samples

The applied study revealed the following results in Table 5 regarding the three sections' initiatives' existence and efficiencies. 
Table 5: The results of the applied studies

\begin{tabular}{|c|c|c|c|c|c|c|}
\hline & $\begin{array}{c}\text { No. of total } \\
\text { proposed } \\
\text { initiatives/ } \\
\text { Section }\end{array}$ & $\begin{array}{c}\text { No. of } \\
\text { achieved } \\
\text { initiatives/ } \\
\text { Section }\end{array}$ & $\begin{array}{c}\text { Ratio } \\
\text { of proposed } \\
\text { section's initiatives/ } \\
\text { Total number of } \\
\text { proposed initiatives } \\
\text { in all sections }\end{array}$ & $\begin{array}{c}\text { The ratio of } \\
\text { achieved } \\
\text { initiatives/ Total } \\
\text { number of } \\
\text { proposed } \\
\text { initiatives per } \\
\text { section }\end{array}$ & $\begin{array}{c}\text { The ratio of the } \\
\text { average } \\
\text { efficiencies } \\
\text { considering the } \\
\text { number of all } \\
\text { initiatives/ Section }\end{array}$ & $\begin{array}{c}\text { The ratio of the } \\
\text { average efficiencies } \\
\text { considering only } \\
\text { the achieved } \\
\text { number of } \\
\text { initiatives/ Sections }\end{array}$ \\
\hline SEMS & 20 & 13 & $20 / 35=57.14 \%$ & $13 / 20=65 \%$ & $38.55 \%$ & $84.15 \%$ \\
\hline SEGSs & 2 & 1 & $2 / 35=5.72 \%$ & $1 / 2=50 \%$ & $2.5 \%$ & $5 \%$ \\
\hline SECSs & 13 & 8 & $13 / 35=37.14 \%$ & $8 / 13=61.4 \%$ & $28.8 \%$ & $46.88 \%$ \\
\hline & 35 & 22 & $100 \%$ & $22 / 35=62.86 \%$ & & \\
\hline
\end{tabular}

Analysis of the initiative's existence in each section:

(a) Analysis of the initiatives in the SEMS section:

No. of total proposed initiatives in this section $=20$ initiatives. No. of achieved initiatives in this section $=13$ initiatives. The ratio of proposed initiatives in this section $=20 /$ total number of proposed initiatives in all sections $35=57.14 \%$. The ratio of achieved initiatives in this section 13/ total number of proposed initiatives per section $20=65 \%$. Regarding the efficiencies of the achieved initiatives, its ratio $=$ $38.55 \%$ considering all initiatives' number in this section $=20$. Simultaneously, it increased to reach $84.15 \%$ when calculating it, considering only the achieved initiatives.

(b) Analysis of the initiatives in the SEGSs section:

No. of total proposed initiatives in this section $=2$ initiatives. No. of achieved initiatives in this section $=1$ initiative. The ratio of proposed initiatives in this section $=2 /$ total number of proposed initiatives in all sections $(35)=5.72 \%$. The ratio of achieved initiatives in this section $=1 /$ total number of proposed initiatives per section (2) $=50 \%$. Regarding the efficiencies of the achieved initiatives, its ratio $=2.5 \%$ considering all initiatives' number in this section (2). Simultaneously, it increased to reach $5 \%$ when calculating it, considering only the achieved initiatives.

\section{(c) Analysis of the initiatives in the SECSs section:}

No. of total proposed initiatives in this section $=13$ initiatives. No. of achieved initiatives in this section $=8$ initiatives. The ratio of proposed initiatives in this section $=13 /$ total number of proposed initiatives in all sections $(35)=37.14 \%$. The ratio of achieved initiatives in this section $=8 /$ total number of proposed initiatives per section $(13)=61.4 \%$. Regarding the efficiencies of the achieved initiatives, its ratio $=28.8 \%$ considering all initiatives' number in this section (13). Simultaneously, it increased to reach $46.88 \%$ when calculating it, considering only the achieved initiatives.

\section{Analysis of the initiatives' efficiency ratio in each section:}

(a) Analysis of SEMS efficiency ratio:

The data listed in Table 4 is embedded in Fig. 5. Besides, it determines each initiative's efficiency ratio, conducting a meaningful result by analyzing the 13 achieved initiatives in this section. Then, the ratio of the average efficiencies considering the number of all initiatives in this section $=$

$(65+50+30+70+75+70+75+75+46+65+70+50+30) /$ $2000=771 / 2000=38.55 \%$ of the total targeted efficiency in this section.

On the other hand, for the 13 achieved initiatives only, this ratio increased to be $771 / 1300=84.15 \%$.

\section{(b) Analysis of SEGS efficiency ratio:}

The data embedded in Fig. 5 determines each initiative's efficiency ratio in this section. The average efficiency ratio considering all initiatives' number in this section $=(5+0) / 200=2.5 \%$ of the total targeted efficiency in this section.

On the other hand, for the only one achieved initiative, this ratio increased to be $5 / 100=5 \%$.

\section{(c) Analysis of SECS efficiency ratio:}

Conducted data in Fig. 5 shows the ratio of the average efficiencies considering the number of all initiatives in this section $=$

$(20+70+65+5+5+70+70+70) / 1300=375 / 1300=$ $28.8 \%$ of the total targeted efficiency in this section.

On the other hand, for the only eight achieved initiative, this ratio increased to be $375 / 800=$ $46.88 \%$. 


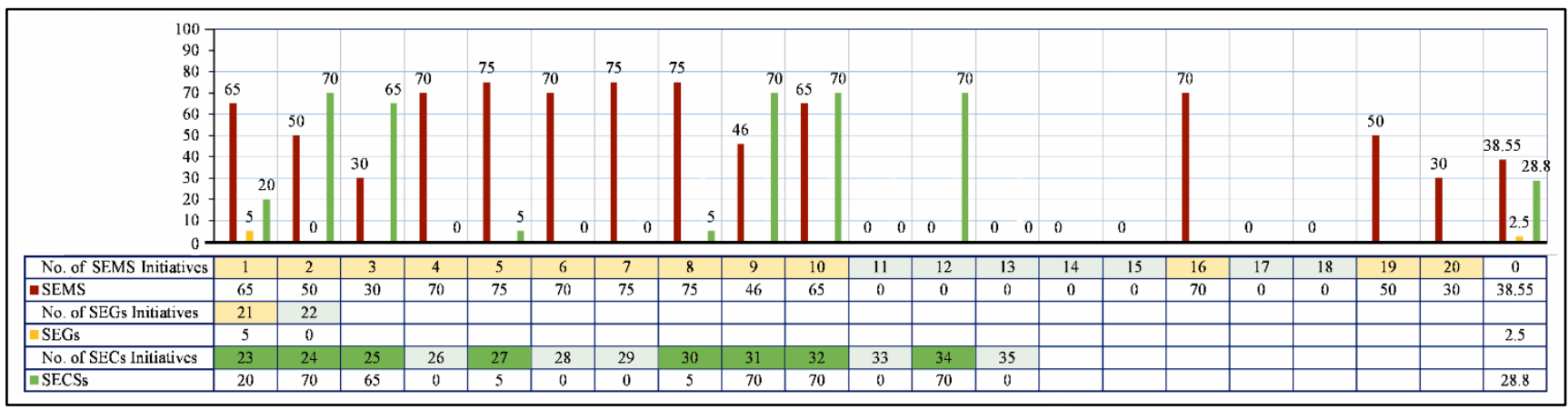

Fig. 5: The percentage of each initiative efficiency for all achieved SESs sections

\section{Discussion}

Implementing absent initiatives will cause higher costs at different levels. Mostly it requires a long time to give their economic benefits significantly. The selection of these initiatives depends on the stakeholders' strategies and long-term goals, with advancements in technologies, data handling, and initiatives' availability. The study expects that SESs will be more efficient and achieve their goals at lower total costs. However, it will not reduce its initial costs due to the syndrome of the permanent rise in the cost of new technologies, considering that they are imported, this is on the one hand.

The previous results gave a logical and remarkable impression of the Egyptian context's reality from this article's research scope. The study ends with these results to strengthen the national vision of Egypt 2030 by presenting the whole developed, tested, and enumerated initiatives. The Egyptian context needs to highlight the absent initiatives for the coming period, giving an excellent potential for boosting sustainability in this path, especially since some existing projects have adequate infrastructure to receive these absent initiatives.

This article addressed and summarized the features of $\underline{\text { SESs, }}$, as illustrated in Table 1. Deep addressing and analysis of the local context pushed the study to link its theoretical findings with it. Therefore, the study developed 35 initiatives focusing on its priorities, relying on a detailed survey through many visits all over Egypt. However, the research point's specialty directed samples' selection to be in the Smart Village, using the developed initiatives listed in Table 2, which checked by many methods to be conducted and linked to the Egyptian reality.

Section II of this study surveyed and verified the developed initiatives in Table 3: Checking what was achieved from the proposed 35 initiatives of SESs in the Egyptian, providing a contribution and a tool in this regard. Hence, the following discussion will address the SESs initiatives in its three sections, as outlined in Table 4, giving a clear sight of its importance, despite the technical, economic, and social obstacles, as follows:

\subsection{Analysis of the first section, SEMS:}

The total initiatives in this section $=20$ of 35 , reflecting its importance, especially it has a top priority in new projects. Nevertheless, for existing buildings, their importance varies according to many factors, including the existing infrastructure, stakeholder requirements, construction function, etc.

Many surveys were conducted to record the achieved initiatives, giving the presented results in Fig. 6.

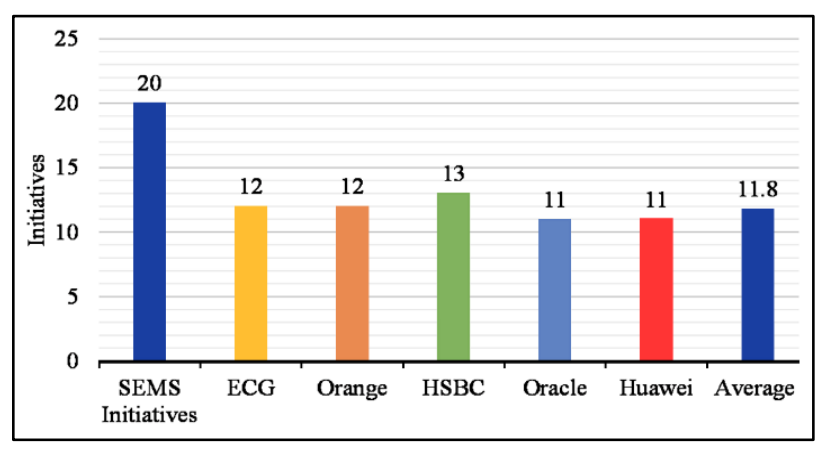

Fig. 6: The SEMS initiatives achieved in the samples

The achieved initiatives in the recorded samples $=$ $12+12+13+11+11=59$ initiatives.

The targeted initiatives for this section $=20$ initiatives $* 5$ samples $=100$ initiatives. The current situation gives a ratio $=59 / 100=59 \%$ for the achieved initiatives. The study noticed that the numbers of the SEMS achieved initiatives are convergent and close to the average number of the initiatives achieved in all samples $=$ the number of these initiatives $/ 5$ samples $=59 / 5=11.8$. 
For the Egyptian context, the SEMS efficiency ratio analysis grants an optimistic view with its excellent performance. Finally, it gives a reasonable deduction that completing the lost initiatives will considerably increase the SESs, especially that the efficiencies in all samples being convergent and recorded high evaluation. So, it can be predicted that each new initiative will be achieved almost will be globalized in the full Egyptian context.

These results give this article its importance in defining the lost initiatives: Nos. 11, 12, 13, 14, 15, 17,18 , that desperately need boosting, as enumerated in Table 6 to set an assessment and interpretation of the Egyptian situation in that regard.

\subsection{Analysis of the second section, SEGSs:}

The study set only two initiatives in this section of 35 , with medium priority and high cost. The achieved initiatives almost disappeared in all samples, where there is only one initiative one sample, as shown in Fig. 7.

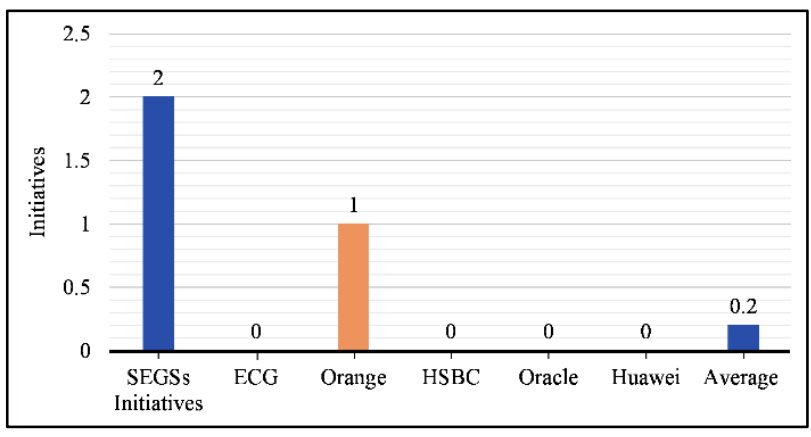

Fig. 7: SEGSs initiatives that achieved in the samples

In this regard, recently, the Egyptian government is seeking to switch to the smart grid. So, it is expected to be used shortly [44].

The study found that the average number of the SECSs initiatives achieved in the five samples $=$ the number of these initiatives $/ 5$ samples $=1 / 5=0.2$ initiatives. So, it gives a reasonable deduction that the Egyptian context desperately needs to concentrate efforts to achieve these two lost initiatives Nos. 21, 22 as a new trend considering energy efficiency and sustainability where it will lead to significant energy savings on a larger scale as a baseline energy supply or as an autonomous storage system.

\subsection{Analysis of the third section, SECSs:}

The number of its initiatives is 13 of 35 , reflecting its importance, especially, it has a top priority in new projects. However, their importance varies according to many factors for existing buildings, as mentioned in section one.

Many surveys were conducted to record the achieved initiatives, giving the presented results in Fig. 8, its achieved initiatives in the recorded samples $=$ $(6+5+6+5+6)=28$ initiatives.

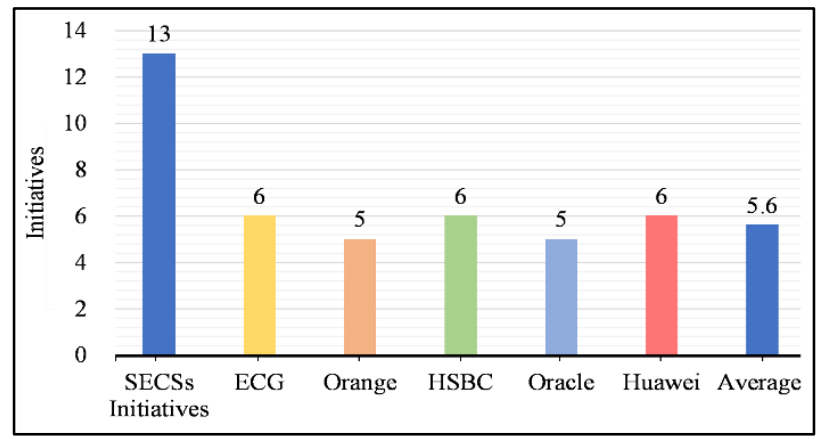

Fig. 8: SECSs initiatives that achieved in the samples

Whereas, the targeted initiatives for this section $=13$ initiatives * 5 samples $=65$ initiatives. The current situation gives a ratio $=28 / 65=43.08 \%$ in this section of the achieved initiatives. The study noticed that the numbers of the SECS achieved initiatives are convergent in all samples, giving an average number of the achieved initiatives in the five samples $=28 / 5$ $=5.6$ initiatives.

As in section one, the SECSs efficiency ratio grants an optimistic view of its performance $(46.88 \%)$, which reasonably urges completing the lost initiatives to increase the SESs total performance, especially with the reasonable and convergent evaluation of efficiencies in all recorded samples. So, it can be predicted that each new initiative will be achieved almost will be spread globally in all Egyptian context.

These results give this article its importance in defining the lost initiatives: Nos. Nos. 26, 28, 29, 33, 35 , which desperately need boosting, as enumerated in Table 6 to set an assessment and interpretation of the Egyptian situation in that regard.

\subsection{Interpreting of losing the absent initiatives}

The applied study aimed to validate the article's hypotheses and complete its objectives by focusing on the absent initiatives and considering them as much-needed initiatives that can be harnessed to boost sustainability. It ended with Table 6 , which enumerated the absent, weak, or no-effect initiatives, attributing this to reasons that focused on the high costs, highly sophisticated technologies, and infrastructure to design, operate and maintain, which is not available in the Egyptian context. 
Table 6: Interpretation of the absent SESs initiatives in the Egyptian context

( Not exist

(1) Fair existence

2 Good existence

3 excellence existence

\begin{tabular}{|c|c|c|c|c|c|c|c|c|c|c|c|}
\hline \multirow{3}{*}{ 氖 } & & \multirow[b]{3}{*}{ The absent/ lost initiatives } & \multicolumn{8}{|c|}{$\begin{array}{l}\text { Situation assessment for } \\
\text { absent/ lost initiatives }\end{array}$} & \multirow[b]{3}{*}{ Interpretation } \\
\hline & $\underline{E}$ & & \multicolumn{3}{|c|}{ Technical } & \multicolumn{3}{|c|}{ Economical } & \multicolumn{2}{|c|}{ Social } & \\
\hline & 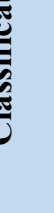 & & 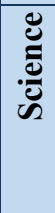 & 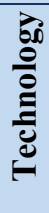 & 递 & 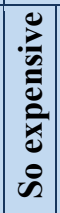 & 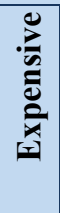 & 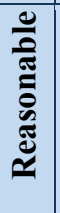 & 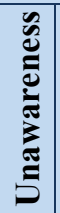 & 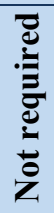 & \\
\hline \multirow{7}{*}{\multicolumn{2}{|c|}{$\sum_{\substack{\infty \\
\infty}}^{\infty}$}} & $\begin{array}{l}\text { 11. Using digital control } \\
\text { where each separate space or } \\
\text { system has an IP address }\end{array}$ & 2 & (1) & $\mathbf{0}$ & & $\checkmark$ & & $\checkmark$ & & $\begin{array}{l}\text { Spaces needed to operate separately and } \\
\text { automatically. This is not available in the Egyptian } \\
\text { context, where it is working manually as one block } \\
\text { from the control center systems by technicians. It } \\
\text { is an additional cost, and it does not exist due to the } \\
\text { lack of widespread application of IoT }\end{array}$ \\
\hline & & $\begin{array}{l}\text { 12. Connecting ESs through } \\
\text { the ethernet networks }\end{array}$ & 3 & 2 & (1) & & $\checkmark$ & & $\checkmark$ & $\checkmark$ & $\begin{array}{l}\text { Ethernet connects SSs to the control panel, } \\
\text { providing faster speeds than some other options for } \\
\text { realizing IoT technologies that have no application } \\
\text { in Egypt yet }\end{array}$ \\
\hline & & $\begin{array}{l}\text { 13. Setting interfaced SEMS } \\
\text { with net-zero energy } \\
\text { consumption }\end{array}$ & (1) & $\mathbf{0}$ & 0 & $\checkmark$ & & & $\checkmark$ & & $\begin{array}{l}\text { It depends on the difference between } \\
\text { energy production and consumption. Egyptian } \\
\text { buildings mainly rely on the government grids }\end{array}$ \\
\hline & & $\begin{array}{l}\text { 14. Promoting the concept of the } \\
\text { internet of things (IoT) }\end{array}$ & (1) & $\mathbf{0}$ & 0 & $\checkmark$ & & & $\checkmark$ & & $\begin{array}{l}\text { The existing required infrastructure does not allow } \\
\text { IoT efficiently operating efficiently }\end{array}$ \\
\hline & & $\begin{array}{l}\text { 15. Using wireless } \\
\text { technologies and cloud } \\
\text { storage }\end{array}$ & 2 & 2 & (1) & & $\checkmark$ & & & $\checkmark$ & $\begin{array}{l}\text { There is no availability to store the user's } \\
\text { preferences on cloud servers. The design processes } \\
\text { do not consider those preferences as it takes the } \\
\text { performance of the systems themselves }\end{array}$ \\
\hline & & $\begin{array}{l}17 . \quad \text { Availability } r \\
\text { integrated, interactive, and } \\
\text { smart spaces }\end{array}$ & 2 & $\boldsymbol{0}$ & (1) & $\checkmark$ & & & $\checkmark$ & $\checkmark$ & $\begin{array}{l}\text { It is not available, the cost is high, and it needs such } \\
\text { advanced technology where the technical scope of } \\
\text { Egypt does not grant it }\end{array}$ \\
\hline & & $\begin{array}{l}\text { 18. Displaying QR codes on } \\
\text { the walls that can be scanned } \\
\text { for information about the } \\
\text { location, mapping, } \\
\text { schedules, and controlling } \\
\text { the energy systems }\end{array}$ & 2 & 2 & (1) & & $\checkmark$ & & $\checkmark$ & $\checkmark$ & $\begin{array}{l}\text { It needs better marketing to illustrate its } \\
\text { importance in buildings }\end{array}$ \\
\hline \multirow{2}{*}{\multicolumn{2}{|c|}{$\sum_{\substack{n \\
0}}^{\infty}$}} & $\begin{array}{l}\text { 21. Adopting renewable } \\
\text { resources as sustainable }\end{array}$ & 2 & (1) & $\boldsymbol{0}$ & $\checkmark$ & & & $\checkmark$ & & $\begin{array}{l}\text { It is relied on the governmental grids as an energy } \\
\text { supplier due to its stability and low price }\end{array}$ \\
\hline & & 22. Applying smart grids & (1) & $\mathbf{0}$ & O & $\checkmark$ & & & $\checkmark$ & & $\begin{array}{l}\text { It is now not available in Egypt and represents one } \\
\text { of the much-needed initiatives to enhance energy } \\
\text { efficiency }\end{array}$ \\
\hline \multirow{3}{*}{$\bigcup_{\tilde{N}}^{\infty}$} & \multirow{3}{*}{$\stackrel{n}{\tilde{n}}$} & $\begin{array}{l}26 . \text { Promote integration } \\
\text { between daylight and } \\
\text { artificial lighting units to } \\
\text { take advantage of natural } \\
\text { resources sustainably }\end{array}$ & 2 & 2 & (1) & & $\checkmark$ & & $\checkmark$ & & $\begin{array}{l}\text { It is scientifically available, technically few, and } \\
\text { primarily lost in practice, although it is } \\
\text { inexpensive and socially can be acceptable with } \\
\text { more adoption and awareness }\end{array}$ \\
\hline & & $\begin{array}{|lll|}\text { 27. The } & \text { widespread } & \text { use of } \\
\text { smart } & \text { lighting } & \text { control } \\
\text { systems } & & \\
\end{array}$ & 2 & (1) & (1) & & $\checkmark$ & & $\checkmark$ & & $\begin{array}{l}\text { Buildings are controlled centrally without the } \\
\text { presence of motion sensors or adjustable control of } \\
\text { users' preferences, but it is considerable and } \\
\text { socially can be acceptable with more awareness }\end{array}$ \\
\hline & & $\begin{array}{l}\text { 28. Utilizing the smart LED } \\
\text { dimming systems }\end{array}$ & (1) & 0 & 0 & & $\checkmark$ & & $\checkmark$ & $\checkmark$ & $\begin{array}{l}\text { There are starting movements to this trend, but } \\
\text { utilizing LED or dimming LED units is not spread } \\
\text { because of the extra cost }\end{array}$ \\
\hline
\end{tabular}




\begin{tabular}{|c|c|c|c|c|c|c|c|c|c|}
\hline & $\begin{array}{l}\text { 29. Measuring the efficiency } \\
\text { of lighting units and } \\
\text { maximizing consumption } \\
\text { rationalization mechanisms }\end{array}$ & (1) & 0 & (0) & & $\checkmark$ & $\checkmark$ & $\checkmark$ & $\begin{array}{l}\text { Measuring is not spread in the Egyptian context; } \\
\text { rationalization mechanisms need more activation } \\
\text { compared with the current situation }\end{array}$ \\
\hline & $\begin{array}{l}\text { 30. Setting the fingerprint } \\
\text { lighting management system }\end{array}$ & (1) & 0 & 0 & $\checkmark$ & & $\checkmark$ & & $\begin{array}{l}\text { Systems that trace the preferences of users is } \\
\text { required, but it is not available in the market }\end{array}$ \\
\hline$\sum^{n}$ & $\begin{array}{l}\text { 33. Promote integration } \\
\text { between ventilation and the } \\
\text { HVAC systems to take } \\
\text { advantage of natural } \\
\text { resources and } \\
\text { enhancing sustainability }\end{array}$ & 2 & (1) & (1) & & $\checkmark$ & $\checkmark$ & & $\begin{array}{l}\text { Activating it in existing buildings needs many } \\
\text { studies, and it may be complicated. In comparison, } \\
\text { this integration in new buildings can be easier with } \\
\text { the available scientific and technical resources. Its } \\
\text { implementation can then be adopted, especially as } \\
\text { it is inexpensive by focusing on the social } \\
\text { dimension that only needs awareness. }\end{array}$ \\
\hline$I$ & $\begin{array}{l}\text { 35. The systems can override } \\
\text { control and automation } \\
\text { systems in HVAC systems as } \\
\text { an option when necessary }\end{array}$ & 2 & 0 & 0 & & $\checkmark$ & $\checkmark$ & & $\begin{array}{l}\text { This initiative was lost in the Egyptian context } \\
\text { because it needs very advanced smart technologies } \\
\text { and needs many studies through which it is } \\
\text { possible to provide the most appropriate solutions } \\
\text { to the occupants according to their needs. }\end{array}$ \\
\hline
\end{tabular}

\section{Conclusion}

Egyptian policies and the 2030 national Agenda adopted both energy efficiency issues and sustainability in all sectors. Architectural studies have a vital role in implementing this agenda's visions and goals. Smart Energy Systems (SESs) improve energy efficiency issues in various sectors through their advanced technologies, including buildings. It supports the performance of buildings' energy at environmental, social, and economic levels. So, the study chose it as an entry point to boost sustainability as a final aim. Previous studies in many disciplines are struggling to increase energy efficiency, and some architectural researches addressed this point. Nevertheless, this study focused on SESs with their potentials to achieve this aim in the Egyptian context.

Egyptian situation has its unique conditions in the scientific, technical, economic ranking, where using advanced high tec is still developed compared with the developed communities in the industrial countries, giving many limitations in harnessing the SESs' potentials in boosting sustainability. Thus, addressing and reviewing similar situations conducted to formularizing implementation's framework, starting with an enumeration of SESs features. The study considered that transformation to this new trend needs to develop a comprehensive plan that relied on defined initiatives as a start phase.

This paper's main contribution is developing and proposing these customized and proper initiatives (35) for the Egyptian context, tracing the global experiments in that scope. It divided these initiatives into three sections, where only 22 initiatives had been recorded in the Egyptian context, representing $62.86 \%$. The first section is SEMS, which is concerned with 20 initiatives; 13 were achieved. The second is SEGSs, which is concerned with two initiatives; one was achieved. The third is SECSs, which is concerned with 13; eight were achieved.

The applied section addressed the gap between the developed initiatives and what already exists in the real context to identify the possibilities and shortcomings through highlighting the absent, weak, or no-effect initiatives. SEMS achieved $38.55 \%$ for all initiatives in terms of efficiencies, and it increased for the existing initiatives to $84.15 \%$. Meanwhile, the efficiency of SEGSs is $2.5 \%$, and it increased for the existing initiatives to $5 \%$. Finally, the efficiency of SECSs achieved $28.8 \%$ for all initiatives; it increased for existing initiatives to $46.88 \%$.

The study provided an assessment and an explanation for the absence, weak, or no-effect 16 initiatives because of their need for the high cost, advanced technology, and infrastructure for design, operation, or maintenance. The statistical studies have revealed that the achieved initiatives' total efficiency has reached $84.15 \%$ for the SEMS section, $5 \%$ for the SEGSs section, and $46.88 \%$ for the SECSs section.

Hence, this article's direct scientific contribution is summarized in developing the necessary initiatives to activate the potential of smart energy systems (SESs) and check them in the Egyptian context to identify those absent initiatives. This scientific contribution also extends to studying those absent initiatives and providing justifications for their absence at technical, economic, and social levels.

Thus, this study can provide an accurate report with 
an action plan indicating the necessity to adopt the developed and defined absent initiatives. The paper's findings target the Egyptian higher political level for adoption in the futuristic plans for the unprecedented contemporary Egyptian urban development, where promoting these SESs lost initiatives will increase the energy efficiency in buildings, as a step to enhance sustainability as an ultimate goal.

On the other hand, in the theoretical and practical scope, this article, through its initiatives, can guide architects and stakeholders to improve energy efficiency in terms of SESs based on each initiative's priority through its impact on resource use, energy savings, informed decisions, improved services, and the risk mitigation, besides, displaying the average cost per each initiative's required systems based on the market prices and products datasheets. Finally, for upcoming research, the absent initiatives should be addressed to be activated on many levels.

\section{References}

[1] Konbr, Usama, Smart Sustainable Cities Vision and Reality. Resourceedings, 2019. 2(1): p. 27. DOI: https://doi.org/10.21625/resourceedings.v2i1.455.

[2] Ceglia, F., P. Esposito, E. Marrasso, and M. Sasso, From smart energy community to smart energy municipalities: Literature review, agendas and pathways. Journal of Cleaner Production, 2020. 254: p. 120118. DOI: https://doi.org/10.1016/j.jclepro.2020.120118.

[3] Mattoni, B., C. Guattari, L. Evangelisti, F. Bisegna, P. Gori, and F. Asdrubali, Critical review and methodological approach to evaluate the differences among international green building rating tools. Renewable and Sustainable Energy Reviews, 2018. 82: p. 950-960. DOI: https://doi.org/10.1016/j.rser.2017.09.105.

[4] Röck, Martin, Marcella Ruschi Mendes Saade, Maria Balouktsi, Freja Nygaard Rasmussen, Harpa Birgisdottir, Rolf Frischknecht, Guillaume Habert, Thomas Lützkendorf, and Alexander Passer, Embodied GHG emissions of buildings - The hidden challenge for effective climate change mitigation. Applied Energy, 2020. 258: p. 114107. DOI:

https://doi.org/10.1016/j.apenergy.2019.114107.

[5] Review, Architectural Science. Low Carbon Buildings and Neighbourhoods. 2020 [cited
202010 October]; Available online: https://think.taylorandfrancis.com/special_issues low-carbon-buildings/.

[6] Komurlu, Ruveyda, David Arditi, and Asli Pelin Gurgun, Applicability of LEED's energy and atmosphere category in three developing countries. Energy and Buildings, 2014. 84: p. 690-697. DOI: https://doi.org/10.1016/j.enbuild.2014.07.095.

[7] Shivakumar, Abhishek, Steve Pye, João Anjo, Michael Miller, Pierre Boutinard Rouelle, Martin Densing, and Tom Kober, Smart energy solutions in the EU: State of play and measuring progress. Energy Strategy Reviews, 2018. 20: p. 133-149. DOI: https://doi.org/10.1016/j.esr.2018.02.005.

[8] Bampou, P., Green buildings for Egypt: a call for an integrated policy. International Journal of Sustainable Energy, 2017. 36(10): p. 994-1009. DOI: https://doi.org/10.1080/14786451.2016.1159207.

[9] IRENA, International Renewable Energy Agency, Renewable Energy Outlook: Egypt. 2018: International Renewable Energy Agency (IRENA). 120.

[10] Pan, J., R. Jain, S. Paul, T. Vu, A. Saifullah, and M. Sha, An Internet of Things Framework for Smart Energy in Buildings: Designs, Prototype, and Experiments. IEEE Internet of Things Journal, 2015. 2(6): p. 527-537. DOI: https://doi.org/10.1109/JIOT.2015.2413397.

[11] Lund, Henrik, Poul Alberg Østergaard, David Connolly, and Brian Vad Mathiesen, Smart energy and smart energy systems. Energy, 2017. 137: p. 556-565. DOI: https://doi.org/10.1016/j.energy.2017.05.123.

[12] Mathiesen, Brian Vad, David Connolly, Henrik Lund, Mads Pagh Nielsen, Erik Schaltz, Henrik Wenzel, Niclas Scott Bentsen, Claus Felby, Per Kaspersen, and Iva Ridjan, CEESA $100 \%$ Renewable Energy Transport Scenarios towards 2050: Technical Background Report Part 2. 2014, Department of Development and Planning, Aalborg University.

[13] Lund, Henrik, Neven Duic, Poul Alberg Østergaard, and Brian Vad Mathiesen, Smart Energy and District Heating: Special Issue dedicated to the 2016 Conference on Smart 
Energy Systems and 4th Generation District heating. Energy, 2018. 160: p. 1220-1223. DOI: https://doi.org/10.1016/j.energy.2018.07.012.

[14] Dincer, Ibrahim and Canan Acar, Smart energy systems for a sustainable future. Applied Energy, 2017. 194: p. 225-235. DOI: https://doi.org/10.1016/j.apenergy.2016.12.058.

[15] Tirado Herrero, Sergio, Larissa Nicholls, and Yolande Strengers, Smart home technologies in everyday life: do they address key energy challenges in households? Current Opinion in Environmental Sustainability, 2018. 31: p. 6570. DOI:

https://doi.org/10.1016/j.cosust.2017.12.001.

[16] Ku, T., W. Park, and H. Choi. IoT energy management platform for microgrid. In 2017 IEEE 7th International Conference on Power and Energy Systems (ICPES). 2017.

[17] Hurtado, L. A., P. H. Nguyen, W. L. Kling, and W. Zeiler. Building Energy Management Systems - Optimization of comfort and energy use. in 2013 48th International Universities' Power Engineering Conference (UPEC). 2013.

[18] Mohamed, N., S. Lazarova-Molnar, and J. AlJaroodi. CE-BEMS: A cloud-enabled building energy management system. in $20163 \mathrm{rd}$ MEC International Conference on Big Data and Smart City (ICBDSC). 2016.

[19] Tan, Y. K., T. P. Huynh, and Z. Wang, Smart Personal Sensor Network Control for Energy Saving in DC Grid Powered LED Lighting System. IEEE Transactions on Smart Grid, 2013. 4(2): p. 669-676. DOI: https://doi.org/10.1109/TSG.2012.2219887.

[20] Zou, Han, Yuxun Zhou, Hao Jiang, Szu-Cheng Chien, Lihua Xie, and Costas J. Spanos, WinLight: A WiFi-based occupancy-driven lighting control system for smart building. Energy and Buildings, 2018. 158: p. 924-938. DOI:

https://doi.org/10.1016/j.enbuild.2017.09.001.

[21] Abedi, Milad, Farrokh Jazizadeh, Bert Huang, and Francine Battaglia. Smart HVAC Systems Adjustable Airflow Direction. 2018. Cham: Springer International Publishing.
[22] Carli, Raffaele, Graziana Cavone, Sarah Ben Othman, and Mariagrazia Dotoli, IoT Based Architecture for Model Predictive Control of HVAC Systems in Smart Buildings. Sensors, 2020. 20(3): p. 781.

[23] Gandenberger, Carsten, Henning Kroll, and Rainer Walz, The role of frugal innovation in the global diffusion of green technologies. International Journal of Technology Management, 2020. 83(1-3): p. 97-113. DOI: https://doi.org/10.1504/IJTM.2020.109218.

[24] Faris, Nizamic, Nguyen Tuan Anh, Lazovik Alexander, and Aiello Marco. GreenMind - An Architecture and Realization for Energy Smart Buildings. in ICT for Sustainability 2014 (ICT4S-14). 2014. Atlantis Press.

[25] Jia, Mengda, Ali Komeily, Yueren Wang, and Ravi S. Srinivasan, Adopting Internet of Things for the development of smart buildings: A review of enabling technologies and applications. Automation in Construction, 2019. 101: p. 111-126. DOI: https://doi.org/10.1016/j.autcon.2019.01.023.

[26] Na, Uikyun and Eun-Kyu Lee, Fog BEMS: An Agent-Based Hierarchical Fog Layer Architecture for Improving Scalability in a Building Energy Management System. 2020. 12(7): p. 2831.

[27] Martirano, L., G. Parise, G. Greco, M. Manganelli, F. Massarella, M. Cianfrini, L. Parise, P. Di Laura Frattura, and E. Habib, Aggregation of Users in a Residential/Commercial Building Managed by a Building Energy Management System (BEMS). IEEE Transactions on Industry Applications, 2019. 55(1): p. 26-34. DOI: https://doi.org/10.1109/TIA.2018.2866155.

[28] Campagna, N., M. Caruso, V. Castiglia, R. Miceli, and F. Viola. Energy Management Concepts for the Evolution of Smart Grids. In 2020 8th International Conference on Smart Grid (icSmartGrid). 2020.

[29] Keyhani, Ali, Design of smart power grid renewable energy systems. 2016: John Wiley \& Sons.

[30] Reddy, Pranavamshu, M. V. N. Surendra Gupta, Srijita Nundy, A. Karthick, and Aritra Ghosh, 
Status of BIPV and BAPV System for Less Energy-Hungry Building in India-A Review. Applied Sciences, 2020. 10(7). DOI: https://doi.org/10.3390/app10072337.

[31] Abdelqawee, IM, Ayman Y Yousef, Khaled M Hasaneen, Maged NF Nashed, and HG Hamed, Standalone Wind Energy Conversion System Control Using New Maximum Power Point Tracking Technique. Int J Emerg Technol Adv Eng Certif J, 2019. 9(2): p. 95-100.

[32] Cicea, Claudiu, Corina Marinescu, and Nicolae Pintilie, Smart cities using smart choices for energy: integrating modern bioenergy in consumption. Theoretical and Empirical Researches in Urban Management, 2019. 14(4): p. 22-34.

[33] Anand, Prashant, David Cheong, Chandra Sekhar, Mattheos Santamouris, and Sekhar Kondepudi, Energy saving estimation for plug and lighting load using occupancy analysis. Renewable Energy, 2019. 143: p. 1143-1161. DOI:

https://doi.org/10.1016/j.renene.2019.05.089.

[34] Jadhav, Nilesh Y., Green and Smart Building Trends, in Green and Smart Buildings: Advanced Technology Options, N.Y. Jadhav, Editor. 2016, Springer Singapore: Singapore. p. 9-14.

[35] Seyedolhosseini, Atefesadat, Nasser Masoumi, Mehdi Modarressi, and Noushin Karimian, Daylight adaptive smart indoor lighting control method using artificial neural networks. Journal of Building Engineering, 2020. 29: p. 101141. DOI:

https://doi.org/10.1016/j.jobe.2019.101141.

[36] Summit, Adria Security. Smart HVAC Systems On Cybersecurity And Connection Protocols Adria Security Summit. 2020 [cited 20216 January]; Available online: https://www.adriasecuritysummit.com/smarthvac-systems-on-cybersecurity-andconnection-protocols.

[37] Deng, Zhipeng and Qingyan Chen, Development and validation of a smart HVAC control system for multi-occupant offices by using occupants' physiological signals from wristband. Energy and Buildings, 2020. 214: p.
109872. DOI:

https://doi.org/10.1016/j.enbuild.2020.109872.

[38] Franklin, 151 North. Chicago office space features. 2020 [cited 202024 August]; Available online: https://151northfranklin.com/features.

[39] Parker, David and Antony Wood, The tall buildings reference book. 2013: Routledge.

[40] BREEAM. The Edge, Amsterdam 2016 [cited 202024 August]; Available online: https://www.breeam.com/casestudies/offices/the-edge-amsterdam.

[41] Wigginton, Michael and Jude Harris, Intelligent Skins. 2013, London: Routledge.

[42] Konbr, Usama, Smart Buildings\& Sustainability in Egypt: Formularization of a Concept and a Methodology Establishing. Journal of Engineering Sciences (JES), 2016. 44(4): p. 472-501. DOI: https://doi.org/10.21608/JESAUN.2016.117613.

[43] Ahmed, Fathi, Waly, and Mohammed Doaa, Helal, The impact of facility management on office buildings performance in Egypt, in Second International Conference on Construction in Developing Countries. 2010, Advancing and Integrating Construction Education, Research \& Practice: Cairo, Egypt.

[44] CGTN. Egypt seeks cooperation with Huawei for smart grid transformation 20204 September [cited 20205 September]; Available online: https://news.cgtn.com/news/2020-09-04/Egyptseeks-cooperation-with-Huawei-for-smartgrid-transformation--TvpKMwola0/index.html.

\section{Creative Commons Attribution}

\section{License 4.0}

\section{(Attribution 4.0 International, CC BY} 4.0)

This article is published under the terms of the

Creative

Commons Attribution License 4.0

https://creativecommons.org/licenses/by/4.0/deed.en_US 